\title{
Effects of Differential DRL Exposure on Interval Timing: Information vs. Inhibition
}

\author{
Matthew L. Eckard
}

Follow this and additional works at: https://researchrepository.wvu.edu/etd

\section{Recommended Citation}

Eckard, Matthew L., "Effects of Differential DRL Exposure on Interval Timing: Information vs. Inhibition" (2017). Graduate Theses, Dissertations, and Problem Reports. 5526.

https://researchrepository.wvu.edu/etd/5526

This Thesis is protected by copyright and/or related rights. It has been brought to you by the The Research Repository @ WVU with permission from the rights-holder(s). You are free to use this Thesis in any way that is permitted by the copyright and related rights legislation that applies to your use. For other uses you must obtain permission from the rights-holder(s) directly, unless additional rights are indicated by a Creative Commons license in the record and/ or on the work itself. This Thesis has been accepted for inclusion in WVU Graduate Theses, Dissertations, and Problem Reports collection by an authorized administrator of The Research Repository @ WVU. For more information, please contact researchrepository@mail.wvu.edu. 


\title{
Effects of Differential DRL Exposure on
}

\section{Interval Timing: Information vs. Inhibition}

\author{
Matthew L. Eckard \\ Thesis submitted \\ to the Eberly College of Arts and Sciences \\ at West Virginia University
}

\begin{abstract}
in partial fulfillment of the requirements of the degree of
Master of Science in Psychology
\end{abstract}

\author{
Karen G. Anderson, Ph.D., Chair \\ Elizabeth G. E. Kyonka, Ph.D. \\ Steven G. Kinsey, Ph.D. \\ Department of Psychology
}

Morgantown, West Virginia

2017

Keywords: Timing precision, timing intervention, peak procedure, mice

Copyright 2017 Matthew L. Eckard 


\begin{abstract}
Effects of Differential DRL Exposure on Interval Timing: Information vs. Inhibition
\end{abstract}

Matthew L. Eckard

Recent investigations focusing on interventions to improve self-controlled choice have centered upon timing processes. However, speculation still remains regarding the mechanism of these interventions. To investigate how these interventions have their effects, timing in mice was assessed using an 18-s peak procedure (18-s FI trials; 54-s peak trials). During an intervention phase, mice in three treatment groups experienced differential reinforcement of low rate (DRL) schedules of reinforcement. A control group received continued exposure to the peak procedure. After 36 DRL sessions, timing was reassessed in the peak procedure. In contrast to previous reports, the DRL intervention resulted in less precise timing as indicated by increased peak spread. It also produced later peak-trial start times and later peak-trial stop times. Thus, it would appear that timing processes may have only been improved in previous reports as a result of assessing timing and choice concurrently and not a result of improvement in timing processes specifically. 


\section{ACKNOWLEDGMENTS}

I would like to thank my fellow lab members in the Quantitative Analysis of Behavior lab Shrinidhi Subramaniam, Daniel Bell-Garrison, Katie Slone, and Paige Patterson. I would also like to thank my advisor Dr. Elizabeth Kyonka, and Selena Engebretson for her technical assistance. This project was supported by the Master's Thesis Award from the WVU Department of Psychology. 


\section{TABLE OF CONTENTS}

Introduction 1

$\begin{array}{ll}\text { Impulsive choice and interval timing } & 1\end{array}$

Timing Interventions $\quad 4$

$\begin{array}{ll}\text { Method } & 7\end{array}$

$\begin{array}{ll}\text { Subjects } & 7\end{array}$

$\begin{array}{ll}\text { Apparatus } & 7\end{array}$

$\begin{array}{ll}\text { Procedure } & 9\end{array}$

$\begin{array}{ll}\text { Pre-training } & 9\end{array}$

$\begin{array}{ll}\text { Fixed-interval training } & 10\end{array}$

Phase 1: FI with peak trials $\quad 10$

Phase 2: DRL intervention 11

Phase 3: FI with peak trials $\quad 12$

$\begin{array}{ll}\text { Data Analysis } & 13\end{array}$

$\begin{array}{lr}\text { Results } & 16\end{array}$

$\begin{array}{ll}\text { Discussion } & 20\end{array}$

$\begin{array}{ll}\text { References } & 27\end{array}$

$\begin{array}{ll}\text { Tables } & 34\end{array}$

$\begin{array}{ll}\text { Figures } & 36\end{array}$

$\begin{array}{ll}\text { Appendix } & 41\end{array}$ 


\section{NONSTANDARD ABBREVIATIONS}

FI - Fixed-Interval schedule of reinforcement

FR - Fixed-ratio schedule of reinforcement

DRL - Differential-Reinforcement-of-Low-Rates schedule of reinforcement

IRT - Interresponse Time

PI - Peak-interval procedure

ITI - Intertrial interval

VAC - Variance accounted for

SEM - Standard error of the mean

ANOVA - Analysis of variance 


\section{Introduction}

Although beginning as separate pursuits, the areas of interval timing and choice have become more related during recent years (Kyonka \& Grace, 2007; Marshall, Smith, \& Kirkpatrick, 2014; Mcclure, Podos, \& Richardson, 2014). The meshing of these research areas has led to investigations about the extent to which interval-timing performance may correlate with and predict delay-discounting performance. The same subjects that display relatively high impulsive choice also perform poorly on timing tasks suggesting that deficits in timing processes may be a central determinant of impulsive choice (Galtress, Garcia, \& Kirkpatrick, 2012;

McClure et al., 2014). Recently, investigations regarding effects of specific timing interventions on subsequent impulsive choice or interval timing have shown an increase in self-control choice and/or temporal precision after the intervention (Renda \& Madden, 2016; Smith, Marshall, \& Kirkpatrick, 2015; Stein et al., 2013; Stein, Renda, Hinnenkamp, \& Madden, 2015). However, the mechanism by which these interventions have their effects has yet to be determined. To further these pursuits, the current investigation attempts to outline how these timing interventions may have affected measures of temporal discrimination, specifically with regard to the interval information and response inhibition hypotheses described below.

Impulsive Choice and Interval Timing

Impulsive behavior can be characterized by the selection of a small, immediate reinforcer at the expense of a larger, delayed reinforcer (Evenden \& Ryan, 1996). The relative decrease in value of a particular reinforcer as a function of its delay has been termed delay discounting. Although the specific behavioral mechanisms of delay discounting and impulsive behavior have proved elusive (Evenden, 1999), delay discounting has provided a laboratory model that has been used to investigate multiple domains of impulsive choice (see Odum, 2011 for a review). 
Repetitive instances of impulsive behavior and increased discounting of delayed rewards are considered to be potential precursors to the development of overall maladaptive behavior including, but not limited to, chronic drug abuse (Moody, Franck, Hatz, \& Bickel, 2016; Perry \& Carroll, 2008), drug relapse (Dallery \& Raiff, 2007; Stranger et al. 2012), gambling (see Wiehler \& Peters, 2015 for a review), and obesity (Rasmussen, Lawyer, \& Reilly, 2010). While evidence suggests that there is a genetic component underlying how impulsive a particular species or strain of animal may be (e.g., Anderson \& Woolverton, 2005; Garcia \& Kirkpatrick, 2013; Pope, Newland, \& Hutsell, 2015), it is certainly the case that there are individual differences within a species or strain (Marshall et al., 2014; Madden, Francisco, Brewer, \& Stein, 2011; Marusich \& Bardo, 2009) and that the extent to which an animal makes impulsive choices is amenable to intervention (Madden et al. 2011; Smith et al., 2015).

Given the severity of behavioral problems that could result from chronic impulsive choice, it is important to consider the development of behavioral interventions to target the potential mechanisms of impulsive choice. However, to implement effective behavioral interventions, one must be familiar with the primary mechanisms of impulsive behavior. A relatively comprehensive review by Evenden (1999) outlined several potential mechanisms of impulsive behavior that could serve as targets for intervention strategies. From this conception, current evidence suggests timing processes to be a primary determinant of impulsive choice (Marshall et al., 2014; McClure et al., 2014; Smith et al., 2015).

Early studies with humans have suggested that timing processes and impulsivity are positively associated. Van den Broek, Bradshaw, and Szabadi have not only shown that individuals who were categorized as "impulsive” performed poorly on a timing task (1987), but also that these individuals reported incorrect temporal estimates in a time reproduction task 
(1992). In addition, individuals with attention-deficit/hyperactivity disorder, a developmental disorder in which impulsivity is a key component, have been shown to choose smaller, immediate reinforcers more often than neurotypical controls (Wilson, Mitchell, Musser, Schmitt, \& Nigg, 2011). This effect has been attributed to the delay aversion hypothesis (Sonuga-Barke, Taylor, Sembi, \& Smith, 1992) implying an inexperience with delays and thus a deficiency in temporal discrimination. Furthermore, studies with typically developing humans have shown that overestimation of temporal intervals and anticipatory perceptions of time are both related to more pronounced delay discounting (Bauman \& Odum, 2012; Kim \& Zauberman, 2009).

Evidence from the animal laboratory also suggests that timing and choice share related processes (Kyonka \& Grace, 2007). McClure and colleagues (2014) showed that there is a positive relation between performance on a delay-discounting task and performance on a peakinterval (PI) task (a derivative of a fixed-interval [FI] schedule of reinforcement) such that increased impulsive choice was directly correlated with imprecise temporal discrimination. Similar results were obtained by Galtress et al. (2012); however, the relation between impulsive choice and timing in their study was not particularly robust. Galtress and colleagues noted that this weak relation might have been due to large procedural differences between the delaydiscounting task and the timing task. These results were followed by Marshall et al. (2014) who found a stronger relation between impulsivity and timing using a temporal-bisection task instead of the PI task. The relation of timing processes and delay discounting is also supported by the finding that acute administration of a drug that increases impulsive choice on a delay-discounting task (Smethells \& Carroll, 2015) also results in premature responding (i.e., imprecise temporal discrimination) on a PI task (Heilbronner \& Meck, 2014). This suggests that timing processes 
may have been affected in both cases, although rate dependency cannot be completely ruled out with regard to PI performance (Odum, Lieving, \& Schaal, 2002).

\section{Timing Interventions}

Due to the accumulating evidence of the relation between interval-timing deficits and impulsive choice, efforts to identify interventions capable of decreasing impulsive choice have centered upon timing processes with the objective of decreasing subsequent impulsive choice. In laboratory experiments with pigeons (Mazur \& Logue, 1978) and applied research with children with intellectual disabilities (Dixon, Rehfeldt, \& Randich, 2003; Neef, Bicard, \& Endo, 2001), an interval fading procedure led to decreased impulsive choice, suggesting promise as an intervention strategy. Additionally, Madden and associates (Renda \& Madden, 2016; Stein et al., 2013; 2015) have noted the success of pre-exposing rats to delayed reinforcement in reducing smaller, sooner reinforcer choice in a subsequent delay-discounting task. In their studies, groups of rats either received chronic exposure to immediate or delayed reinforcers (17.5-s delay) prior to being tested on a delay-discounting task. They found that groups pre-exposed to delayed reinforcement showed an increased preference for large, delayed reinforcers relative to immediate-exposure groups. This effect not only generalized to a longer delay than was present in the delay pre-exposure (30 s), but also showed a residual effect in a 120-day follow-up assessment (Renda \& Madden, 2016). Madden et al. (2011) reported similar results by exposing rats to mixed delays (either $0.01 \mathrm{~s}$ and $20 \mathrm{~s}$ or $20 \mathrm{~s}$ and $60 \mathrm{~s}$ ) during an intervention resulting in decreased impulsive choice for about half of the subjects.

Outcomes of these pre-exposure studies have led to the development of two likely candidates for the mechanism responsible. The first of these is that the delays provide some degree of information about the relevant delay associated with a reinforcer (Madden et al., 2011). 
Simply stated, the more exposed a subject is to a particular delay to reinforcement, the less sensitive that subject will be to subsequent delays leading to an overall increase in the selection of delayed reinforcers. However, this interpretation is primarily concerned with exposures to delays that match delays that may be experienced in a testing environment. Another potential mechanism is that forced exposure to delayed reinforcement reduces an aversion to those delayed reinforcers. Indeed, in the typical delay-discounting procedure (Evenden \& Ryan, 1996), a preference shift away from large, delayed reinforcers indicates an aversive quality of the delay. This interpretation indicates that exposure to ever-lengthening intervals would reduce the aversiveness of the various delays experienced in a testing environment resulting in an increased preference for delayed reinforcers.

Along these lines, Smith et al. (2015) conducted a series of experiments examining the influence of multiple timing interventions on subsequent impulsive choice and timing in rats. In each experiment, impulsive choice was assessed using a modified delay-discounting task in which temporal discrimination was assessed by a PI task embedded in the choice task. Each experiment only differed with respect to the type of schedule used in the timing intervention. In Experiment 1, a differential-reinforcement-of-low-rates (DRL) schedule was used. The contingencies of a DRL schedule are such that the inter-response time (IRT; the elapsed time between two responses) has to meet a certain interval requirement $(t)$. If the responding meets this requirement (IRT $\geq t$ ), then reinforcement is delivered. If a response occurs too early (IRT $<$ $t$ ), then the interval is reset. The duration of the DRL interval was either $10 \mathrm{~s}$ or $30 \mathrm{~s}$ to match the delay to reinforcement on either alternative during the initial delay-discounting task. Experiment 2 used an FI or variable interval (VI) schedule as the intervention. The contingencies of a VI schedule are similar to an FI schedule except that the intervals in the VI schedule are variable 
durations that then average to the specified schedule duration. The FI and VI schedule values were also made identical to the delays in the delay-discounting task (10 s and $30 \mathrm{~s}$ ). They found that the DRL and FI/VI interventions led to similar reductions in impulsive choice as well as similar increases in temporal precision via parameters derived from a fitted Gaussian function. One interpretation of the observed increase in temporal precision is that the DRL schedule resulted in inhibited responding, and this inhibition carried over to the subsequent PI task. Alternatively, it is possible that the DRL, which typically had the same interval value as the PI task, provided additional information about that interval.

Although these previous studies have shown that interventions are successful in reducing impulsive choice, they were not designed to find out why or how these interventions have their effects. There is some evidence to suggest that increased precision of temporal discrimination is at the core of these interventions (Matell \& Portugal, 2007; Sanabria, Thrailkill, \& Killeen, 2009; Smith et al., 2015). Matell and Portugal (2007) corroborate the results of Heilbronner and Meck (2014) with respect to premature responding on a PI task. They showed that temporal discrimination on a PI task became more precise with the addition of a secondary response alternative that allowed for a reduction of premature responses on the primary response alternative. Similar results were obtained by Sanabria et al. (2009) in which the presence of a concurrent schedule tightened the overall temporal discrimination gradient. Thus, the previously noted timing interventions may have had their effects through increasing overall response inhibition, which in turn affects impulsive choice by altering the precision of temporal discrimination.

Taken together, the results of these intervention studies suggest that timing processes may account for the results seen in previous delay-exposure studies (Madden et al., 2011; Renda 
\& Madden, 2016; Stein et al. 2013; 2015). The results from Smith and colleagues’ (2015) Experiment 1 suggest that exposure to the same intervals in the intervention as those used in the delay-discounting task may be responsible for the obtained results, but because a range of DRL requirements was not assessed, it is not possible to determine whether the DRL exposure functioned to dampen response rates generally (inhibition hypothesis) or to provide additional training with the PI duration (information hypothesis).

There is accumulating evidence to suggest that timing processes are an important determinant of impulsive choice (Bauman \& Odum, 2012; Marshall et al., 2014; McClure et al. 2014). This evidence has been the basis for specific interventions that focus on temporal parameters, the implementation of which has led to successful decreases in impulsive choice (Renda \& Madden, 2016; Smith et al., 2015; Stein et al., 2013; 2015) and improvements in temporal precision (Smith et al., 2015). However, data from Smith et al. (2015) show similar improvements in timing precision and decreases in impulsive choice as a result of two different types of interventions (DRL and FI/VI).

As previously noted, Smith and colleagues’ (2015) DRL intervention could be interpreted as operating by either of two different processes. If the function of the DRL intervention was to inhibit responding, the observed decrease in peak spread would be a consequence of a global decline in response rate. However, the DRL intervention could have also functioned to increase overall exposure to the interval of the PI schedule, increasing timing precision by providing additional training to that interval. Furthermore, the difference in experimental procedures across the assessment and intervention phases of Smith and colleagues' study further complicates the interpretation of the intervention effect with regard to the predominant mechanism responsible. 
Thus, the goal of present study was to attempt to isolate the process by which a DRL schedule might lead to increases in timing precision.

\section{Method}

Subjects

Twenty-seven experimentally naïve male C57/BL 6J mice were used as subjects, and were six weeks old upon arrival. Mice were housed three per cage in a vivarium operating on a 12/12-hour light cycle. Mice acclimated in the vivarium for three days prior to training. Sessions were conducted seven days per week between the hours of 0830 - 1800 during the subjects' light cycle. Water was freely available in the vivarium, and food was restricted to $7 \mathrm{~g}$ of chow per cage per day. All protocols were approved by the Animal Care and Use Committee of West Virginia University under ACUC protocol \#15-0606.

\section{Apparatus}

Nine MED-Associates ${ }^{\circledR}$ mouse operant-conditioning chambers enclosed within a soundattenuating box were used for data collection. Six of the chambers had dimensions measuring $17.8 \mathrm{~cm}$ long $\mathrm{x} 15.2 \mathrm{~cm}$ wide $\mathrm{x} 18.4 \mathrm{~cm}$ high, and three of the chambers had dimensions measuring $21.6 \mathrm{~cm}$ long x $17.8 \mathrm{~cm}$ wide x $12.7 \mathrm{~cm}$ high. The work panel of the chambers consisted of two nose-poke holes spaced $9 \mathrm{~cm}$ apart, both of which could be illuminated from inside the nose-poke hole by a small yellow LED bulb. Head entries into the active nose-poke were detected by breaks in an infrared photobeam. A $0.5 \mathrm{~cm}$ diameter yellow stimulus light positioned $2.5 \mathrm{~cm}$ above each nose-poke served as the cue for nose-poke activation. Equidistant between both nose-poke holes was a $2.5 \mathrm{~cm}$ diameter opening for which $15 \%$ sucrose water delivered at a volume of 0.01 cc could be accessed by way of a dipper cup. The nose-poke and dipper holes were positioned $1.2 \mathrm{~cm}$ above a stainless-steel grid floor consisting of 19 horizontal 
bars (0.25 cm diameter). A houselight centered $10 \mathrm{~cm}$ above the grid floor on the back wall opposite the work panel illuminated the interior of the chamber during sessions. The door, side panel, and ceiling of the chamber were constructed of clear polycarbonate. A built-in fan on the wall of the sound-attenuating box provided ventilation and white noise during sessions. Each operant-conditioning chamber was connected to a MED-Associates ${ }^{\circledR}$ interface operated by a desktop computer in an adjacent room using MED-PC notation.

\section{Procedure}

Pre-training. In pre-training, the nose-poke response was established using an autoshaping procedure (Balci et al., 2010; Brown \& Jenkins, 1968). In this procedure, 15\% sucrose water was made available according to a conjoint fixed-time (FT) $60 \mathrm{~s}$, fixed-ratio (FR) 1 schedule in which reinforcement was delivered upon the completion of either schedule, whichever occurred first. That is, 15\% sucrose water was presented once every minute independent of responding (FT 60 s) but also immediately whenever a nose-poke response occurred (FR 1). The FT 60-s schedule was reset following each reinforcer presentation. Each trial began with the illumination of the houselight, active nose-poke aperture, and the stimulus light above the active nose-poke aperture. During reinforcer presentations, the nose-poke light and stimulus light above the nose-poke aperture were extinguished and the houselight flashed on and off in 0.5-s increments for a total of five seconds of reinforcer presentation. This reinforcer duration remained in effect for the entire study. There was no inter-trial interval (ITI) during pre-training. Each pre-training session terminated after 60 reinforcers had been delivered. The pre-training phase lasting for 14 sessions. The autoshaping procedure was not successful for 15 of the mice, so hand shaping was used to establish the nose-poke response for those mice. Hand shaping involved video recording the mouse in the operant chamber during sessions with the experimenter delivering a reinforcer 
contingent on a response that closely approximated the nose-poke response (e.g., sniffing near the nose-poke aperture).

Fixed-interval (FI) training. Following nose-poke shaping, mice began FI training. Initially, an FI 2-s schedule was in effect for two sessions. Then, an FI 4-s schedule was in effect for two sessions followed by an FI 8-s for five sessions followed by an FI 12-s schedule for six sessions. Prior to the second FI 12-s session, a limited hold of 3 s was introduced. A limited hold requires that a response occur prior to a time requirement. In this case, a response had to occur after the FI criterion time elapsed but before $3 \mathrm{~s}$ following the FI criterion to be reinforced. Because of a high number of trial omissions (a response not occurring between 18 - 22 s after stimulus onset) after imposing the limited hold, a variable 20-s ITI was introduced prior to the fourth session of the FI 12-s schedule. After the sixth FI 12-s session, the terminal FI 18-s schedule was introduced. Sessions terminated after 60 reinforcers were earned or 90 minutes elapsed, whichever occurred first. Upon trial onset, the houselight, active nose-poke aperture, and the stimulus light above the active nose-poke aperture were illuminated, and the FI timer started. Once a response occurred following the criterion time, reinforcement was delivered as described in pre-training. Responses occurring prior to the criterion time were recorded but had no other programmed consequence.

Phase 1: FI with peak trials. After 17 sessions of training on the 18-s FI schedule, peak trials were interspersed within each session. During a peak trial, all stimuli in the chamber were identical to the stimuli associated with the FI schedule except that the trial duration was extended to 54 s (FI criterion multiplied by three), and responses were recorded but not reinforced. Once peak trials were implemented, each session consisted of 45 reinforced FI trials and 15 nonreinforced peak trials. In Phase 1, each session terminated after 45 reinforcers were delivered or 
90 minutes elapsed, whichever occurred first. Phase 1 was in effect for a total of 25 sessions. The last 10 sessions were analyzed to determine pre-intervention measures.

After 25 sessions in Phase 1, mice were separated into four groups (three groups of seven mice and one group of six) for the subsequent intervention phase. Groups were matched in terms of average peak spread. Peak spread was calculated by fitting a ramped Gaussian function to normalized response rates for each mouse. Analysis of variance confirmed that there were no statistically significant group differences in terms of overall peak spread, $F(3,23)=0.133, p=$ .93 , or response rate, $F(3,23)=.192, p=.90$, prior to Phase 2 (see data analysis for a more complete description of model fitting, group assignment, and statistical tests).

Phase 2: DRL intervention. After 25 sessions in Phase 1, all but one group of mice (PI 18) were trained on differing DRL schedules. Groups 1, 2, and 3 experienced a DRL 9-s, 18-s, and 27-s schedule, respectively. The PI-18 group acted as a control group by remaining in Phase 1 for the duration of the study. Pizzo, Kirkpatrick, and Blundell (2009) suggested that training DRL responding using progressive increases in the DRL criterion to establish a target criterion can come with some potential training difficulties. For this reason, the three DRL groups began Phase 2 on the target DRL criterion as opposed to experiencing progressive training as in the FI training phase.

Initially, DRL sessions terminated after 60 reinforcers were delivered or two hours had elapsed, whichever occurred first. The two-hour time limit was established because it was expected all mice would be able to earn all available reinforcers in that time. In principle, it was possible for mice in all groups to complete sessions within about 35 minutes. However, because the majority of mice in the DRL-18 and DRL-27 groups were not obtaining 60 reinforcers per session in the first eight sessions, the session duration was extended to three hours for a 
subsequent seven sessions. After this second determination of DRL acquisition using three-hour sessions, group differences in mean number of reinforcers earned per session decreased but did not disappear. Within-group discrepancies with respect to reinforcers earned per session remained. In the DRL-27 group, for example, three mice earned at least 53 reinforcers per session, two mice earned at least 45 reinforcers, and two mice earned only 22 reinforcers on average. Because longer sessions would have made the running day impractically long, it was determined that the best course of action was to keep the conditions as is with the three-hour session duration.

Sessions during Phase 2 began similarly to sessions during Phase 1 with regard to the illumination of stimuli in the chamber. During DRL sessions, only responses with IRTs that satisfied the required interval were reinforced. Responses with an IRT shorter than the required interval reset the interval. The DRL timer did not begin until a single response was made resulting in a response-initiated DRL schedule. The response-initiated component was used to ensure that the reinforcer duration was not included as part of an IRT. Reinforcer presentation during Phase 2 was similar to Phase 1 and training sessions. Phase 2 was in effect for a total of 38 sessions (eight two-hour sessions and 30 three-hour sessions). The last five sessions were analyzed to determine stable DRL responding as indicated by IRT distributions.

Phase 3: FI with peak trials. The purpose of Phase 3 was to determine effects of the DRL intervention. Phase 3 was identical to Phase 1 in all respects using the same FI 18-s schedule with a 3-s LH, variable 20-s ITI, and 54-s peak trials. Sessions in Phase 3 terminated after 45 reinforcers were delivered or 90 minutes elapsed, whichever occurred first. This phase was in effect for 25 sessions. 


\section{Data Analysis}

To characterize overall peak-trial responding during Phases 1 and 3, normalized response gradients during peak trials were aggregated across trials and a ramped Gaussian function was fitted to the data. The ramped Gaussian was defined as

$$
y(t)=e^{-(t-b)^{2 / 2 c^{2}}}+\left(m(t)+y_{1}\right)
$$

where $t$ is the normalized elapsed time since trial onset, $b$ is the normalized time since trial onset at which the normalized response rate peaks (peak time), $c$ is the standard deviation of the function (peak spread), $m$ is the slope of the linear function fitted to the rightward tail of the distribution, and $y_{1}$ is the y-intercept of that linear function. Peak trials were divided into 1-s time bins and a local response rate was determined (aggregated across peak trials) within each 1-s bin. These response rates were then divided by the highest response rate, or the peak rate, which yielded a normalized rate within each 1-s time bin.

Measures of peak time and peak spread were used to estimate the accuracy and precision of peak-trial responding, respectively, of each group in Phases 1 and 3. Timing accuracy is the extent to which the peak time aligns with the criterion time of reinforcement, and timing precision refers to the width of the peak function. A high peak spread is indicative of poor timing precision (a wide peak function) whereas a low peak spread is indicative of precise timing (a narrow peak function).

To assign groups for the DRL intervention, mean peak spread across the last 10 sessions of Phase 1 was derived using Equation 1 for each mouse. Overall response rates were also determined. The mice were then ranked from highest to lowest in terms of peak spread. This list was divided into four sections of six mice each. From each of the four sections, one mouse was assigned to each group using matched random assignment. A one-way analysis of variance 
(ANOVA) on estimates of Phase 1 peak spread with group as the factor was conducted to confirm that the groups were evenly matched such that mean peak spread and response rate were not significantly different across groups prior to the DRL intervention.

Phase 2 (DRL intervention) data were analyzed by measuring the frequency with which various IRTs occurred to determine how well obtained IRTs coincided with the IRT requirement of the various DRL schedules. IRTs were characterized by a frequency distribution, which plotted the frequency with which predefined IRTs occur. IRT durations were defined in 0.5-s bins ranging from $0-.5 \mathrm{~s}$ to $49.5-50 \mathrm{~s}$. Any IRTs above $50 \mathrm{~s}$ were counted as “50+”. Average IRT was also calculated for each mouse.

Because a Gaussian analysis can overlook some important single-trial response characteristics (Church, Meck, \& Gibbon, 1994; Taylor, Horvitz, \& Balsam, 2007), a low-highlow analysis was also conducted to characterize peak-trial responding. Performance during single FI trials has been shown to follow a low-high pattern such that response rate is low at the beginning of the trial then abruptly switches to a high rate that typically persists until reinforcement delivery (Schneider, 1969). When the reinforcer is not delivered (peak trials), response rate follows a low-high-low pattern where response rate is initially low, abruptly switches to a high rate prior to the criterion time of reinforcement (start time), stabilizes for some duration, and switches back to a low rate after the criterion time (stop time) (Church, et al., 1994). These measures are considered decision thresholds, which are not detected by a Gaussian analysis.

For this single-trial analysis, the start time and stop time were defined using an index that conducts an exhaustive search of all possible temporal locations of start and stop times that maximize the time difference between the high-rate and low-rate states (Church et al., 1994). 
The index that was maximized was defined as $L S_{1}\left(r-r_{\mathrm{LS} 1}\right)+H S\left(r_{\mathrm{HS}}-r\right)+L S_{2}\left(r-r_{\mathrm{LS} 2}\right)$ where $L S_{1}, H S$, and $L S_{2}$, are the period of the trial before the start time, the period of high response rate after the start and before the stop time, and the remaining time from the stop time until the end of the peak trial, respectively. The variables $r_{\mathrm{LS} 1}, r_{\mathrm{HS}}$, and $r_{\mathrm{LS} 2}$ are the response rates within each respective time period during the trial, and $r$ is the mean response rate for the entire peak trial. This index assumes the start of the high state can begin at any one response during a trial except the last response, and the end of the high state can begin at any subsequent response to the response that marks the start time. The primary measures of the low-high-low analysis were start time, stop time, high-state duration (stop time - start time), and midpoint ([start time + stop time] / 2). The statistical tests used to assess group differences on individual-trial measures were identical to those used to analyze peak time, peak spread and response rate.

To assess effects of the DRL intervention on temporal discrimination in Phase 3, a 4 $(\text { group) } \times 3 \text { (time; pre-DRL, post-DRL(E), post-DRL(L) })^{1}$ mixed-factorial ANOVA was conducted with group as the between-subjects factor and time as the within-subjects factor. Measures characterized by this analysis included peak spread, peak time, response rate, start time, stop time, high-state duration, and midpoint. In addition to these tests, start and stop time were also determined for single sessions during the final 10 sessions of Phase 1 and the first 10 sessions of Phase 3. For this analysis, each session in Phase 3 was compared to the average of the last 10 sessions in Phase 1. A 4 (group) $\times 11$ (session) mixed-factorial ANOVA was conducted with group as the between-subjects factor and session as the within-subjects factor. When significant group or pre-post differences were found, Tukey’s HSD post-hoc tests were conducted. If sphericity was violated, then a Greenhouse-Geisser correction was applied. All statistical analyses assumed an alpha level of .05.

\footnotetext{
1 “E” (early) refers to the first 10 sessions of Phase 3 whereas "L” (late) refers to the last 10 sessions of Phase 3.
} 
Because of unforeseen procedural difficulties during the DRL intervention, results were analyzed in two ways - for all mice $(\mathrm{N}=27)$ and for only those mice that earned at least 55 of the 60 possible reinforcers per session on average during the last five DRL sessions $(\mathrm{N}=23)$. Analyses excluding those mice that did not complete DRL sessions were conducted to exclude an interpretation of the results being due to schedule mastery discrepancies within groups. However, identical conclusions were drawn as a result of both sets of analyses suggesting that within-group differences in the number of reinforcers earned on the DRL schedule did not affect the outcome of the intervention and the overall interpretation of the results. The data that are reported below include all mice. Figures and tables of the analyses excluding mice are included as an Appendix.

\section{Results}

As was noted above, analyses of variance confirmed that the matched random assignment was successful at producing groups with equivalent Phase 1 peak spread and response rate prior to the DRL intervention. During the DRL intervention, there was evidence of control by the DRL schedule in that longer DRL-schedule durations produced longer IRTs. Mean IRT increased as a function of DRL group: DRL $9(M=2.6, S E M=.27)$, DRL $18(M=4.47, S E M=$ .53), DRL $27(M=5.62, S E M=.27)$.

Figure 1 depicts results of the Gaussian analysis as well as response rates for each group across all time points. The top panel shows mean ( \pm SEM) peak spread. There was no main effect of group. Peak spread was significantly higher after the intervention, $F(2,46)=12.812, p<.001$, but only at the first post-DRL time point. A group $\times$ pre-post interaction was also evident, $F(6$, 46) $=3.187, p<.05$. Post-hoc tests showed the DRL-18 and DRL-27 groups qualified this interaction. Peak spread for the DRL-18 group at the first post-DRL time point $(M=12.5, S E M$ 
$=1.02)$ was higher than that of the pre-DRL $(M=10.05, S E M=.51)$ and second post-DRL time point $(M=10.09, S E M=.59)$. Similarly, peak spread for the DRL-27 group at the first post-DRL time point $(M=13.28, S E M=1.08)$ was higher than pre-DRL values $(M=10.15, S E M=.44)$ for that group. The DRL intervention did not affect peak spread in the DRL-9 and PI-18 groups. Exposure to longer DRL schedules increased peak spread, but the effect was transient and dissipated before the $25^{\text {th }}$ session of Phase 3 .

The middle panel of Figure 1 shows mean $( \pm S E M)$ peak time. Peak times were near $18 \mathrm{~s}$ for all groups, indicating accurate timing of the FI. There were no differences in peak time across groups or time points suggesting that the DRL intervention acted primarily on timing precision (spread) as opposed to timing accuracy (peak time). Table 1 shows all statistical results of the Gaussian analysis. The bottom panel of Figure 1 shows mean $( \pm S E M)$ response rate for each group. There was considerable intersubject variability in response rates within all groups, but there was no significant effect of the DRL intervention on response rates (see Table 1). At all time points, average response rate for each group did not decrease below 120 responses per minute. Group mean response rates ranged from 122 - 152 responses per minute across all time points. The assumption of sphericity held for all repeated measures factors related to the Gaussian analysis.

Figure 2 shows start and stop times derived from the single-trials analysis. The top panel shows mean ( $\pm S E M$ ) start time for each group across all time points. There was no main effect of group. Start times were significantly increased after the DRL intervention, $F(1.73,39.78)=$ 7.29, $p<.01$. However, a group $\times$ pre-post interaction was not evident, $F(5.19,39.78)=2.42, p$ $=.0508$. The bottom panel of Figure 2 shows mean $( \pm$ SEM) stop time. There was a main effect of time such that stop times were later after the DRL intervention, $F(2,46)=9.19, p<.001$. A 
group $\times$ time interaction was also evident, $F(6,46)=2.50, p<.05$. Post hoc tests showed that stop time of the DRL-27 group at the first post-DRL time point $(M=37.81$, $S E M=1.86)$ was significantly later than pre-DRL stop time for that group $(M=33.7, S E M=1.62)$. This was the only group to show significant pre-post results with respect to stop time. Again, there were no changes in the DRL-9 and PI-18 groups.

The top panel of Figure 3 shows mean $( \pm S E M)$ high-state duration for each group across all time points. There were no differences across groups or time points in terms of high-state duration. Statistical results of the low-high-low analysis are shown in Table 2. The bottom panel of Figure 3 shows mean $( \pm S E M)$ midpoint for each group across all time points. There was no main effect of group. Midpoints were shifted rightward after the DRL intervention $F(1.69$, $39.02)=9.68, p<.01$. A group $\times$ time interaction was also evident $F(5.08,39.02)=2.73, p<$ .05. This interaction was qualified by the DRL-27 group having significantly delayed midpoints initially after the intervention $(M=26.985, S E M=2.15)$ relative to before $(M=22.37, S E M=$ .812). The DRL-27 group was the only group to show significant pre-post results with respect to midpoint.

Figure 4 shows start time (top panel) and stop time (bottom panel) for each group during the last 10 sessions of Phase 1 and the first 10 sessions of Phase 3. This analysis was conducted to differentiate the relatively similar effects of the DRL intervention on start and stop times depicted in Figure 2. Start times were significantly delayed after the DRL intervention $F(4.46$, $102.62)=24.47, p<.001$. A group $\times$ time interaction was also evident $F(13.38,102.61)=3.46$, $p<.001$. Compared to Phase 1 , the first three sessions of Phase 3 for the DRL-27 group, first two sessions of the DRL-18 group, and the first session of the DRL-9 group were significantly different from their respective Phase 1 averages. No other Phase 3 sessions showed an increase 
in start time. When viewed session-by-session, stop times were not significantly elevated within any one session relative to Phase 1 . It is important to note that start time was initially affected but stabilized after the third session in the most extreme case (DRL-27 group), and stop times showed a consistent pattern across Phase 3 .

Thus, the only effects of the DRL intervention detected by the Gaussian and low-highlow analyses were temporary increases in peak spread, start time, and stop time for mice exposed to longer DRL schedules with no effect on peak times or response rates. Given the ordinal nature of the effect on these measures when averaged across sessions, it is possible that the observed difference may have been a function of obtained rate of reinforcement during the DRL intervention. Mean $( \pm S E M)$ reinforcement rate during the last five DRL sessions for each group is plotted in the top panel of Figure 5 . There was a significant main effect of group $F(1,3)=$ 32.6, $p<.0001$. Post-hoc analyses showed that all groups were significantly different from one another. Ordered from highest to lowest, reinforcement rates were: DRL $9(M=1.114, S E M=$ $.08)>$ PI $18(M=.79, S E M=.03)>$ DRL $18(M=.57, S E M=.06)>$ DRL $27(M=.318, S E M=$ .05). The bottom panel of Figure 4 shows peak spread early in Phase 3 for each mouse in each group as a function of the obtained reinforcement rate (reinforcers per min.) during the last five sessions of the DRL. For the PI-18 group, the same days were used for analysis as for the DRL groups. While there was a significant negative correlation between reinforcement rate and peak spread, $r(25)=-0.458, p<.02$, this relation did not hold within groups.

\section{Discussion}

The purpose of the present study was to extend the findings of Smith and colleagues’ (2015) Experiment 1. Specifically, it was an attempt to identify a potential mechanism regarding the timing precision improvements associated with the DRL intervention reported in that study. 
These mechanisms follow two hypotheses put forth by Madden and associates (Madden et al., 2011; Stein et al., 2013; 2015) regarding delay exposure (information) or decreased delay aversion (inhibition) to be responsible for timing and choice improvements. As a general description of timing engendered by the peak procedure, the current data showed aggregated peak trial response patterns to be approximately Gaussian with peaks in response rate occurring near the criterion time. Results of the Gaussian analysis indicated that the DRL intervention primarily affected timing precision as opposed to timing accuracy. In other words, the DRL intervention did not appear to affect the accuracy of interval timing (i.e., when response rate reached its peak during peak trials), but rather, it affected the precision with which the interval was timed (i.e., greater or fewer responses early and late during peak trials). However, in contrast to Smith et al. (2015), the present study found that a DRL intervention generally increased peak spread (i.e., precision decreased). This effect on peak spread was also group- and timedependent. Early in Phase 3, peak spread was increased but only for the DRL-18 and DRL-27 groups. It is possible that this effect on peak spread could have been the result of poor Gaussian fits (i.e., low variance accounted for [VAC] by the model). However, during the early portion of Phase 3, VAC was above $82 \%$ for each mouse with the majority of the fits falling between $90 \%$ 98\% VAC indicating Gaussian-shaped response gradients during peak trials. Peak spread subsequently returned to baseline levels after continued exposure to the peak procedure.

Because a Gaussian analysis is an analytical tool using aggregated peak trials to estimate model parameter values, a single-trials analysis, often referred to as a low-high-low analysis (Church et al., 1994), was also conducted to characterize timing behavior on individual trials. This analysis showed that start and stop times were affected briefly after the DRL intervention when these measures were averaged across sessions. Both start and stop time were shifted 
rightward for the DRL-27 group, but only start time was shifted rightward for the DRL-18 group. There were no apparent effects of the DRL intervention on single-trial response characteristics of the DRL-9 group. Upon closer inspection of start and stop times across individual sessions, the DRL intervention affected start and stop times differently. Whereas start times were initially delayed by more than a factor of two for all DRL groups relative to Phase 1, stop times were not delayed during any specific session. Also, start times for all DRL groups recovered relatively quickly whereas stop times remained at a similar temporal location throughout Phase 3.

In terms of the inhibition and information hypotheses previously put forth, the current data do not show conclusive evidence for either. This conclusion is largely due to the DRL intervention either having no substantive effect (DRL 9) or leading to less precise timing (DRL 18 and DRL 27). For response inhibition to be responsible for the observed effects, a negative linear relation between peak spread and DRL requirement would need to be present, which as Figure 1 shows, was not the case. Assuming individual-trial response measures were the only measure of temporal discrimination gathered, it could be concluded that inhibition was driving the effects by shifting start times rightward, closer to the 18-s time marker. However, peak spread increased suggesting a decrement in temporal precision. If interval exposure (information) were to be driving the effects, then a U-shaped relation between DRL requirement and peak spread would need to be present such that the DRL-18 group would have shown the greatest improvement in timing. This effect was not observed. One would also expect the PI-18 group to have shown a significant improvement in peak spread due to continued exposure to the 18-s interval without any punishment contingency for premature responding. However, no significant improvements were detected in the control group. 
Instead, the longest DRL intervention appeared to have a greater suppressive effect on responding early in Phase 3 relative to late in Phase 3. This is evidenced from the session-bysession data showing the DRL intervention degraded temporal control of start times without a corresponding change in stop times. It is generally accepted that the threshold for start time is independent of the threshold for stop time (Cheng \& Westwood, 1993; Church et al., 1994; Kyonka \& Grace, 2010; Matell \& Portugal, 2007). In addition to the current study, one such example is provided by Kyonka and Grace (2007) in which they showed stop time increased as a function of FI duration whereas start time remained relatively static suggesting stop time, but not start time, was more sensitive to the current FI. Because of the relative vulnerability of start time as compared to stop time, it is assumed that this threshold independence comes about by alternative processes influencing start time. Indeed, selective effects on start time have been observed after administration of dopaminergic drugs (Saulsgiver, McClure, \& Wynne, 2006; Taylor et al., 2007) as well as with changes in reinforcer magnitude (Galtress \& Kirkpatrick, 2009; Ludvig, Conover, \& Shizgal, 2007). However, in an attempt to induce an asymmetrical shift in the peak response distribution, Cheng (1992) punished early responses within each trial in a discrete-trial peak procedure. If responses occurred before six seconds after trial onset, then the trial ended without an opportunity for reinforcement. Instead of selectively affecting the left half of the distribution (start time) when the punishment was in effect, the entire distribution became narrower suggesting an overall tightening of temporal control. The current DRL intervention was successful in effectively punishing early responding in each group through delaying start times more considerably than stop times in Phase 3, but this effect led to a general deterioration of temporal control as shown by the Gaussian analysis. 
With the aim of isolating the timing process from any explicit choice contingency, one methodological difference of note in the current study was the use of a single-operant procedure as opposed to a concurrent procedure (Smith et al., 2015). With regard to improving temporal control, it has been shown that the use of concurrent schedules can lead to more precise temporal generalization gradients (Matell \& Portugal, 2007; Sanabria et al., 2009). However, the use of concurrent schedules to induce sharper peak functions is typically done in the interest of opportunity cost (Sanabria et al., 2009). In these procedures, reinforcement will be set up on one of two alternatives each trial, and the subject can freely alternate between the two options to satisfy the operative schedule. One schedule is an FI schedule, and the other is typically a VI (Matell \& Portugal, 2007), random ratio, or random-interval schedule (Sanabria et al., 2009). Responding on one schedule means "missing out" on potentially available reinforcement on the other. Relative to no opportunity cost (only the FI schedule is operative), opportunity cost induces rightward shifts in start time closer to the FI criterion (Matell \& Portugal, 2007; Sanabria et al., 2009) and leftward shifts in stop time (Sanabria et al., 2009) therefore increasing temporal control on the FI alternative. Thus, the introduction of an uncertain alternative could be said to increase the salience of the certain alternative. Alternatively, Fox, Prue, and Kyonka (2016) showed that sensitivity to two concurrently elapsing FI schedules (only one FI pays off each trial) can lead to increased variance in response distributions whenever the short FI increases in proportion along with the long FI across conditions as opposed to when the short FI remains at a constant value relative to the long FI. This represents the possibility that sensitivity to two FI schedules within a given procedure can systematically influence estimates of temporal control. However, a discrete-trial choice procedure does not allow for switching (Smith et al., 2015). Indeed, data reported by Smith et al. show behavior to be sensitive to both delays (10 and $30 \mathrm{~s}$ ) 
as evidenced by modes of peak functions coinciding with the FI criteria. Thus, while switching between alternatives was not possible in Smith and colleagues' procedure, it seems likely that exposure to two different delays affected the outcome of the DRL intervention, though at present it is not clear why.

A potential caveat of the current study is that reinforcement rate during the DRL intervention was not equated across groups. While Smith et al. (2015) did not account for reinforcement rate either, a predominant theory of timing suggests higher or lower reinforcement rates can lead to narrower or wider temporal generalization gradients, respectively (Killeen \& Fetterman, 1988). Although, it is unlikely that this intergroup difference during the intervention was a main determinant of Phase 3 performance. The relation between DRL reinforcement rate and Phase 3 peak spread suggests that while reinforcement rate during Phase 2 did generally correlate with Phase 3 peak spread, this relation did not hold within groups. If it were the case that reinforcement rate predicted the Phase 3 outcome, then one might also expect a series of relatively lean VI schedules to produce a similar outcome. However, the main determinant appeared to be the contingency set up by the DRL schedule, which was to suppress responding to differing degrees across groups. Thus, interpreting the intervention effects as being driven by Phase 2 reinforcement rate seems to lack generality to other experimental scenarios.

Mentioned previously, the threshold for the start of the high state in the peak procedure is thought to be influenced by processes other than timing (Kyonka \& Grace, 2007; 2010). These adulterating influences are evidenced by the consistent finding that start times are more variable from trial to trial than are stop times (Cheng \& Westwood, 1993; Church et al., 1994, Matell \& Portugal, 2007). While not directly applicable to a choice contingency, perhaps the present results could inform how a DRL schedule could be used to induce less variability in start times. 
Earning reinforcers on a typical DRL schedule involves the timing of IRTs instead of an external stimulus onset as in an FI schedule. However, with regard to "time markers," the onset of an external stimulus has been shown to produce more precise timing in the peak procedure relative to a response-initiated peak procedure (Fox \& Kyonka, 2015) with similar improvements on signaled DRL schedules relative to unsignaled DRL schedules (Marcucella, Macdonall, Munro, \& Moseley, 1977; Tripp \& McNaughton, 1991; Wiley, Compton, \& Golden, 2000; but see also Caetano \& Church, 2009). On a signaled DRL schedule, a stimulus light will either be illuminated or extinguished when a reinforcer becomes available (IRT $\geq t$ ). The introduction of the signal results in a notable reduction in burst responding (IRT $<1 \mathrm{~s}$ ) as well as sharper peaks in IRT frequency at the IRT criterion. More importantly, it functionally shifts stimulus control from the subjects' behavior to an external cue. Thus, the stimulus controlling behavior is more analogous between tasks allowing for 1) potentially quicker training during the DRL phase and 2) no differentiation in stimulus context between phases. To clarify the latter point, if the onset of the nose-poke aperture were to signal reinforcement availability during the DRL, then that stimulus would be correlated with general reinforcement availability throughout the study instead of punishment during the DRL phase. The decrease in start time variability would likely come about by more consistent post-reinforcement pauses during the DRL phase that would then presumably carry over to the peak procedure.

Being that sensitivity to intervals of time is a crucial aspect to behaving effectively in many environments, determining methods to increase timing accuracy and precision is both interesting and worthwhile. Take exercise for example. Say a relatively inexperienced jogger can jog two miles in about 20 minutes. However, jogging is a fairly aversive activity to most and time seems to “drag on” in most instances. In other words, time is overestimated. This may lead 
the jogger to check the time of his/her run frequently, which results in the jogger slowing down and inadvertently self-reinforcing an observing response. If this observing response happens frequently enough during the jog, then the jog may take longer than anticipated (say, 23 minutes) or may end prematurely. Thus, in a very simple case, improving temporal discrimination could have an impact on something as common as exercise efficiency.

Nonetheless, while the current study cannot speak to effects of DRL interventions on choice, the present results suggest that they do not always engender more precise temporal control. The present study showed that temporal control was deteriorated in an ordinal fashion with respect to the DRL requirement, and did not appear to improve beyond baseline levels through continued exposure to the peak procedure. This initial effect was likely due to the suppressive nature of the DRL contingency. It is still unclear as to how the reinforcement context (single operant vs. choice), stimulus context (external cue vs. response-initiated cues), and the targeted process (response inhibition vs. interval exposure) may interact to affect the outcomes of these interventions. Perhaps future studies may consider these unexplored interactions when designing novel interventions or replicating previous ones. 


\section{References}

Anderson, K.G. \& Woolverton, W. L. (2005). Effects of clomipramine on self-control choice in Lewis and Fischer 344 rats. Pharmacology, Biochemistry, and Behavior, 80(3), 387-393. doi: 10.1016/j.pbb.2004.11.015

Bauman, A. A., \& Odum, A. I. (2012). Impulsivity, risk taking and timing. Behavioural Processes, 90, 408-414. doi: 10.1016/j.beproc.2012.04.005

Caetano, M. S., \& Church, R. M. (2009). A comparison of responses and stimuli as time markers. Behavioural Processes, 81, 298-302. doi:10.1016/j.beproc.2009.01.014

Cheng, K. (1992). The form of timing distributions in pigeons under penalties for responding early. Animal Learning \& Behavior, 20(2), 112-120.

Cheng, K., \& Westwood, R. (1993). Analysis of Single Trials in Pigeons’ Timing Performance. Journal of Experimental Psychology: Animal Behavior Processes, 19(I), 56-67.

Church, R. M., Meck, W. H., \& Gibbon, J. (1994). Application of scalar timing theory to individual trials. Journal of Experimental Psychology: Animal Behavior Processes, 20, 135-155.

Dallery, J., \& Raiff, B. R. (2007). Delay discounting predicts cigarette smoking in a laboratory model of abstinence reinforcement. Psychopharmacology, 190, 485-496. doi: 10.1007/s00213-006-0627-5

Dixon, M. R., Rehfeldt, R. A., \& Randich, L. (2003). Enhancing tolerance to delayed reinforcers: the role of intervening activities. Journal of Applied Behavior Analysis, 36(2), 263-6. https://doi.org/10.1901/jaba.2003.36-263 
Evenden, J. L. (1999). Varieties of impulsivity. Psychopharmacology, 146, 348-361.

Evenden, J. L., Ryan, C. N. (1996). The pharmacology of impulsive behaviour in rats: The effects of drugs on response choice with varying delays of reinforcement. Psychopharmacology, 128, 161-170.

Fox, A. E. \& Kyonka, E. G. E. (2015). Timing in response-initiated fixed intervals. Journal of the Experimental Analysis of Behavior, 103(2), 375-392. doi: 10.1002/jeab.120

Fox, A. E., Prue, K. E., \& Kyonka, E. G. E. (2016). What is timed in a fixed-interval temporal bisection procedure? Learning \& Behavior, 44, 366-377. doi: 10.3758/s13420-0160228-Z

Galtress, T., Garcia, A., \& Kirkpatrick, K. (2012). Individual differences in impulsive choice and timing in rats. Journal of the Experimental Analysis of Behavior, 98, 65-87. doi: 10.1901/jeab.2012.98-65

Garcia, A., \& Kirkpatrick, K. (2013). Impulsive choice behavior in four strains of rats: Evaluation of possible models of Attention-Deficit/Hyperactivity Disorder. Behavioural Brain Research, 238, 10-22.

Kyonka, E. G. E., \& Grace, R. C. (2007). Rapid acquisition of choice and timing in pigeons. Journal of Experimental Psychology: Animal Behavior Processes, 33(4), 392-408. doi: 10.1037/0097-7403.33.4.392

Kyonka, E. G. E., \& Grace, R. C. (2010). Rapid acquisition of choice and timing and the provenance of the terminal-link effect. Journal of the Experimental Analysis of Behavior, 94(2), 209-225. doi: 10.1901/jeab.2010.94-209 
Heilbronner, S. R., Meck, W. H. (2014). Dissociation between interval timing and intertemporal choice following administration of fluoxetine, cocaine, or methamphetamine. Behavioural Processes, 101, 123-134. doi: 10.1016/j.beproc.2013.09.013

Killeen, P. R., \& Fetterman, J. G. (1988). A behavioral theory of timing. Psychological Review, 95(2), 274-295.

Kim, B. K., \& Zauberman, G. (2009). Perception of anticipatory time in temporal discounting. Journal of Neuroscience, Psychology, and Economics, 2(2), 91-101.

Ludvig, E. A., Conover, K., \& Shizgal, P. (2007). The effect of reinforcer magnitude on timing in rats. Journal of the Experimental Analysis of Behavior, 87(2), 201-218. doi: 10.1901/jeab.2007.38-06

Madden, G. J., Francisco, M. T., Brewer, A. T., \& Stein, J. S. (2011). Delay discounting and gambling. Behavioural Processes, 87, 43-49. doi: 10.1016/j.beproc.2011.01.012

Marcucella, H., Macdonall, J. S., Munro, I., \& Moseley, V. (1977). Presignaled behavior as a predictor of signaled DRL performance. Bulletin of the Psychonomic Society, 10(4), 335-338.

Marshall, A. T., Smith, A. P., Kirkpatrick, K. (2014). Mechanisms of impulsive choice: I. Individual differences in interval timing and reward processing. Journal of the Experimental Analysis of Behavior, 102(1), 86-101. doi: 10.1002/jeab.88

Marusich, J. A., \& Bardo, M. T. (2009). Differences in impulsivity on delay-discounting task predict self-administration of a low unit dose of methylphenidate in rats. Behavioral Pharmacology, 20, 447-454. doi: 10.1097/FBP.0b013e328330ad6d 
Matell, M. S., \& Portugal, G. S. (2007). Impulsive responding on the peak-interval procedure. Behavioural Processes, 74, 198-208. doi:10.1016/j.beproc.2006.08.009

Mazur, J. E., \& Logue, A. W. (1978). Choice in a self-control paradigm: Effects of a fading procedure. Journal of the Experimental Analysis of Behavior, 30, 11-17.

McClure, J., Podos, J., \& Richardson, H. N. (2014). Isolating the delay component of impulsive choice in adolescent rats. Frontiers in Integrative Neuroscience, 8, 1-9. doi: 10.3389/fnint.2014.00003

Moody, L., Franck, C., Hatz, L., \& Bickel, W. K. (2016). Impulsivity and polysubstance use: A systematic comparison of delay discounting in mono-, dual-, and trisubstance use. Experimental and Clinical Psychopharmacology, 24(1), 30-37. doi: 10.1037/pha0000059

Neef, N. A., Bicard, D. F., \& Endo, S. (2001). Assessment of impulsivity and the development of self-control in students with attention deficit hyperactivity disorder. Journal of Applied Behavior Analysis, 34, 397-408.

Odum, A. L. (2011). Delay discounting: I'm a k, you're a k. Journal of the Experimental Analysis of Behavior, 96, 427-439. doi: 10.1901/jeab.2011.96-423

Odum, A. L., Lieving, L. M., \& Schaal, D. W. (2002). Effects of d-amphetamine in a temporal discrimination procedure: Selective changes in timing or rate dependency? Journal of the Experimental Analysis of Behavior, 78, 195-214.

Perry, J. L., Carroll, M. E. (2008). The role of impulsive behavior in drug abuse. Psychopharmacology, 200, 1-26. doi: 10.1007/s00213-008-1173-0 
Pizzo, M. J., Kirkpatrick, K., Blundell, P. J. (2009). The effect of changes in criterion value on differential reinforcement of low rate schedule performance. Journal of the Experimental Analysis of Behavior, 92, 181-198. doi: 10.1901/jeab.2009.92-181

Pope, D. A., Newland, C. M., Hutsell, B. A. (2015). Delay-specific stimuli and genotype interact to determine temporal discounting in a rapid-acquisition procedure. Journal of the Experimental Analysis of Behavior, 103, 450-471. doi: 10.1002/jeab.148

Rasmussen, E. B., Lawyer, S. R., \& Reilly, W. (2010). Percent body fat is related to delay and probability discounting for food in humans. Behavioural Processes, 83, 23-30. doi:10.1016/j.beproc.2009.09.001

Renda, C. R., \& Madden, G. J. (2016). Impulsive choice and pre-exposure to delays: III. Fourmonth test-retest outcomes in male wistar rats. Behavioural Processes, 126, 108-112. doi: 10.1016/j.beproc.2016.03.014

Sanabria, F., Thrailkill, E. A., \& Killeen, P. R. (2009). Timing with opportunity cost: Concurrent schedules of reinforcement improve peak timing. Learning \& Behavior, 37(3), 217229. doi: 10.3758/LB.37.3.217

Saulsgiver, K. A., McClure, E. A., \& Wynne, C. D. L. (2006). Effects of d-amphetamine on the behavior of pigeons exposed to the peak procedure. Behavioural Processes, 71(2-3), 268-285. https://doi.org/10.1016/j.beproc.2005.12.005

Smethells, J. R., \& Carroll, M. E. (2015). Discrepant effects of acute cocaine on impulsive choice (delay discounting) in female rats during an increasing- and adjusting-delay procedure. Psychopharmacology, 232, 2455-2462. doi: 10.1007/s00213-015-3874-5 
Smith, A. P., Marshall, A. T., \& Kirkpatrick, K. (2015). Mechanisms of impulsive choice: II. Time-based interventions to improve self-control. Behavioural Processes, 112, 29-42. doi: 10.1016/j.beproc.2014.10.010

Sonuga-Barke, E. J. S., Taylor, E., Sembi, S., \& Smith, J. (1992). Hyperactivity and delay aversion - I. The effect of delay on choice. The Journal of Child Psychology and Psychiatry, 33, 387-398.

Stranger, C., Ryan, S. R., Fu, H., Landes, R. D., Jones, B. A., Bickel, W. K., Budney, A. J. (2012). Delay discounting predicts adolescent substance abuse treatment outcome. Experimental and Clinical Psychopharmacology, 20, 205-212. doi: 10.1037/a0026543

Stein, J. S., Johnson, P. S., Renda, C. R., Smits, R. R., Liston, K. J., Shahan, T. A., \& Madden, G. J. (2013). Early and prolonged exposure to reward delay: Effects of impulsive choice and alcohol self-administration in male rats. Experimental and Clinical Psychopharmacology, 21, 172-180. doi: 10.1037/a0031245

Stein, J. S., Renda, C. R., Hinnenkamp, J. E., \& Madden, G. J. (2015). Impulsive choice, alcohol consumption, and pre-exposure to delayed rewards: II. Potential mechanisms. Journal of the Experimental Analysis of Behavior 103(1), 33-49. doi: 10.1002/jeab.116

Taylor, K. M., Horvitz, J. C., \& Balsam, P. D. (2007). Amphetamine affects the start of responding in the peak interval timing task. Behavioural Processes, 74, 168-175. doi:10.1016/j.beproc.2006.11.005

Toplak, M. E., Dockstader, C., \& Tannock, R. (2006). Temporal information processing in ADHD: Findings to date and new methods. Journal of Neuroscience Methods, 151, 1529. doi:10.1016/j.jneumeth.2005.09.018 
Tripp, G., \& McNaughton, N. (1991). Naloxone and chlordiazepoxide: Effects on acquisition and performance of signalled punishment. Pharmacology, Biochemistry and Behavior, 38(1), 43-47. https://doi.org/10.1016/0091-3057(91)90587-R

Wiehler, A., \& Peters, J. (2015). Reward-based decision making in pathological gambling: The roles of risk and delay. Neuroscience Research, 90, 3-14. doi:10.1016/j.neures.2014.09.008

Wiley, J. L., Compton, a D., \& Golden, K. M. (2000). Separation of drug effects on timing and behavioral inhibition by increased stimulus control. Experimental and Clinical Psychopharmacology, 8(4), 451-461. doi: 10.1037/1064-1297.8.4.451

Wilson, V. B., Mitchell, S. H., Musser, E. D., Schmitt, C. F., \& Nigg, J. T. (2011). Delay discounting of reward in ADHD: Application in young children. The Journal of Child Psychology and Psychiatry, 52, 256-264. doi:10.1111/j.1469-7610.2010.02347.x

van den Broek, M. D., Bradshaw, C. M., Szabadi, E. (1987). Behaviour of “impulsive” and “nonimpulsive” humans in a temporal differentiation schedule of reinforcement. Personality and Individual Differences, 8, 233-239.

van den Broek, M. D., Bradshaw, C. M., \& Szabadi, E. (1992). Performance of impulsive and non-impulsive subjects on two temporal differentiation tasks. Personality and Individual Differences, 13(2), 169-174. 
Table 1. ANOVA (main effects and interaction effects) results of the Gaussian analysis.

\begin{tabular}{|c|c|c|c|}
\hline & & Peak spread & \\
\hline & $F$ & $p$ & $\eta^{2}$ \\
\hline Group & 1.838 & .17 & .193 \\
\hline Pre-Post & 12.812 & $<.001$ & .357 \\
\hline \multirow[t]{3}{*}{ Group $\times$ Pre-Post } & 3.187 & .01 & .294 \\
\hline & & Peak time & \\
\hline & $F$ & $p$ & $\eta^{2}$ \\
\hline Group & .793 & .51 & .09 \\
\hline Pre-Post & 2.011 & .14 & .08 \\
\hline \multirow[t]{3}{*}{ Group $\times$ Pre-Post } & .744 & .62 & .08 \\
\hline & & Response rate & \\
\hline & $F$ & $p$ & $\eta^{2}$ \\
\hline Group & .04 & .98 & .005 \\
\hline Pre-Post & 1.97 & .15 & .529 \\
\hline Group $\times$ Pre-Post & .86 & .53 & .101 \\
\hline
\end{tabular}


Table 2. ANOVA results of the low-high-low analysis.

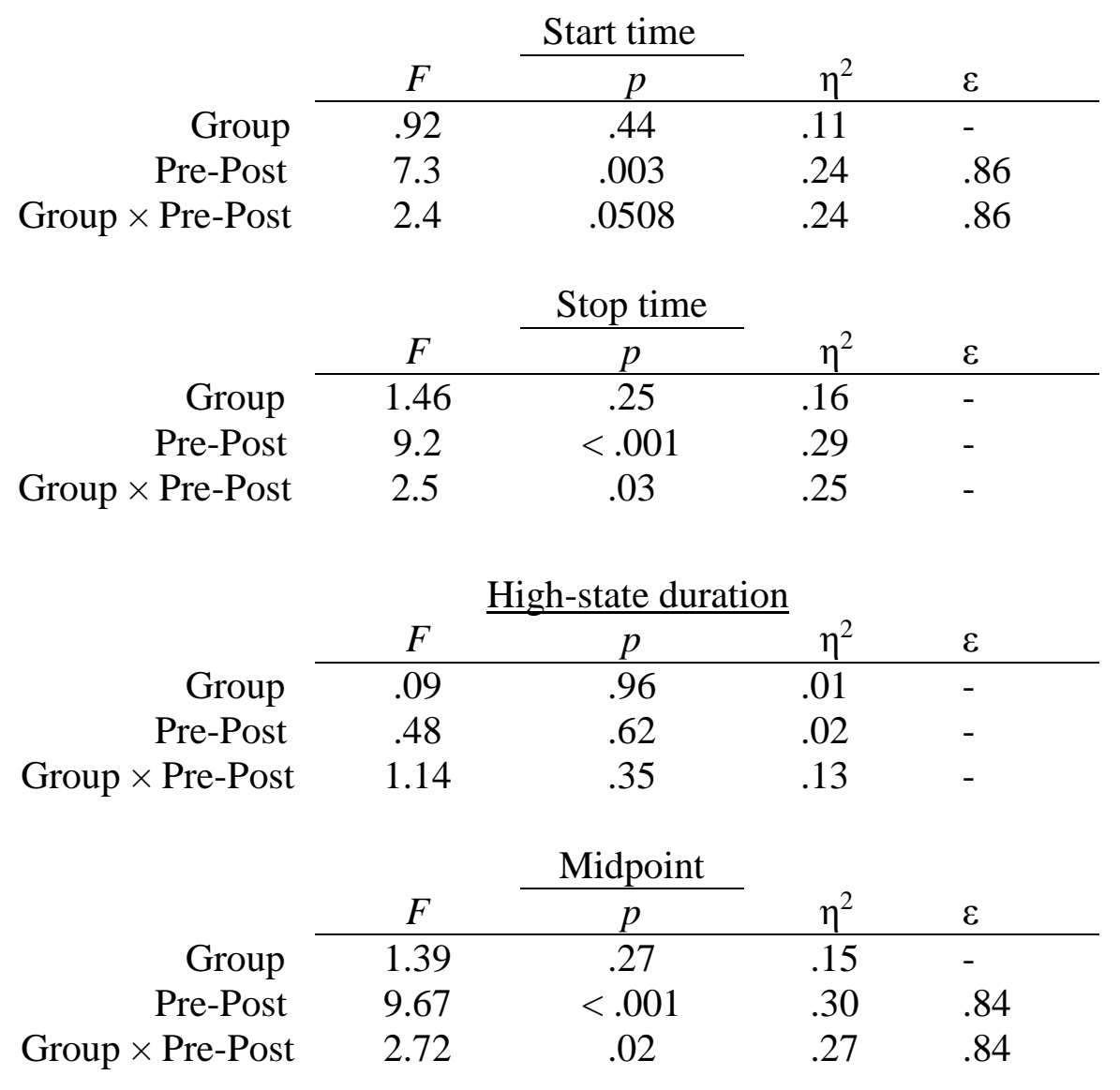

Note. Epsilon values are given for cases in which sphericity was violated. 

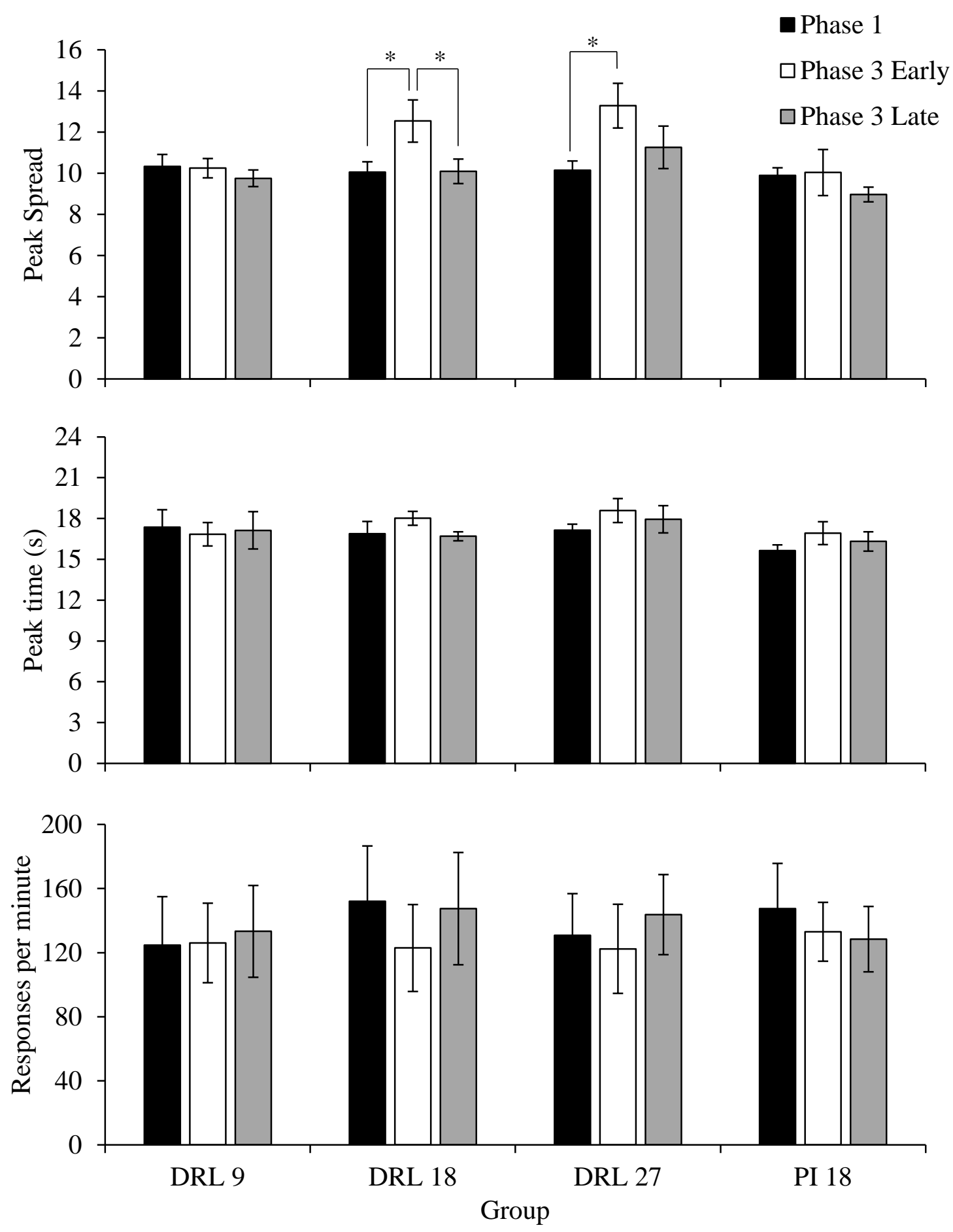

Figure 1. Results of the Gaussian analysis for each group at each time point. Top panel: Mean $( \pm S E M)$ peak spread. Middle panel: Mean $( \pm S E M)$ peak time. Bottom panel: Mean $( \pm S E M)$ response rate. Black bars show pre-DRL measures. White bars show measures of timing just after the DRL intervention from session $2-11$ post-DRL. Grey bars show measures of timing after stability was reached (sessions $15-25$ post-DRL). ${ }^{*} p<.05$ 

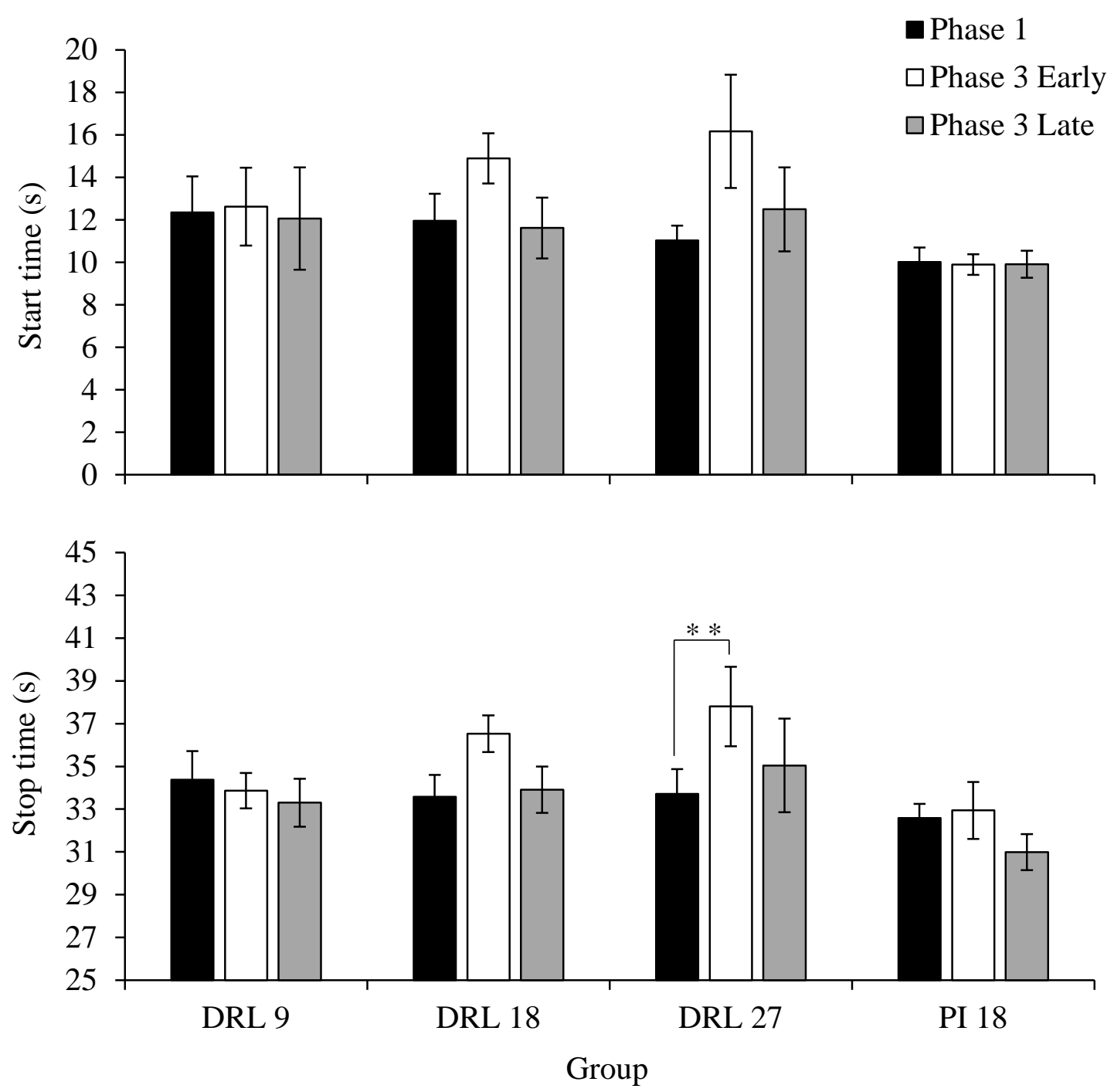

Figure 2. Results of the low-high-low analysis for each group at each time point. The top panel shows mean $( \pm S E M)$ start time. The middle panel shows mean $( \pm S E M)$ stop time. The bottom panel shows mean $( \pm S E M)$ high-state duration. The legend is identical to Figure $1 .{ }^{* *} p<.01$ 

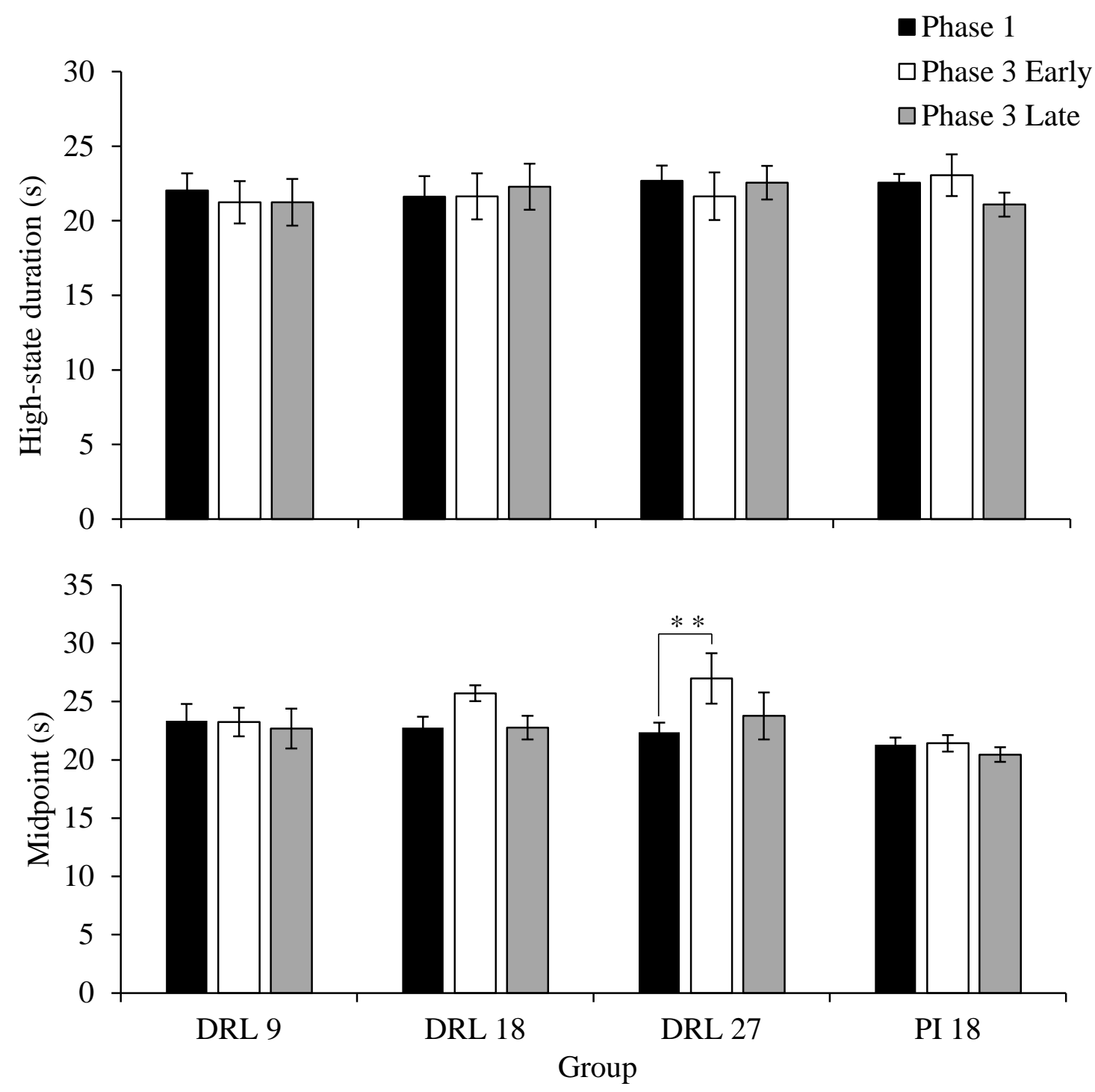

Figure 3. Top panel: Mean $( \pm S E M)$ high-state duration is plotted for each group at each time point. Bottom panel: Mean $( \pm S E M)$ midpoint is plotted for each group at each time point. The legend is similar to previous figures. ${ }^{* *} p<.01$ 


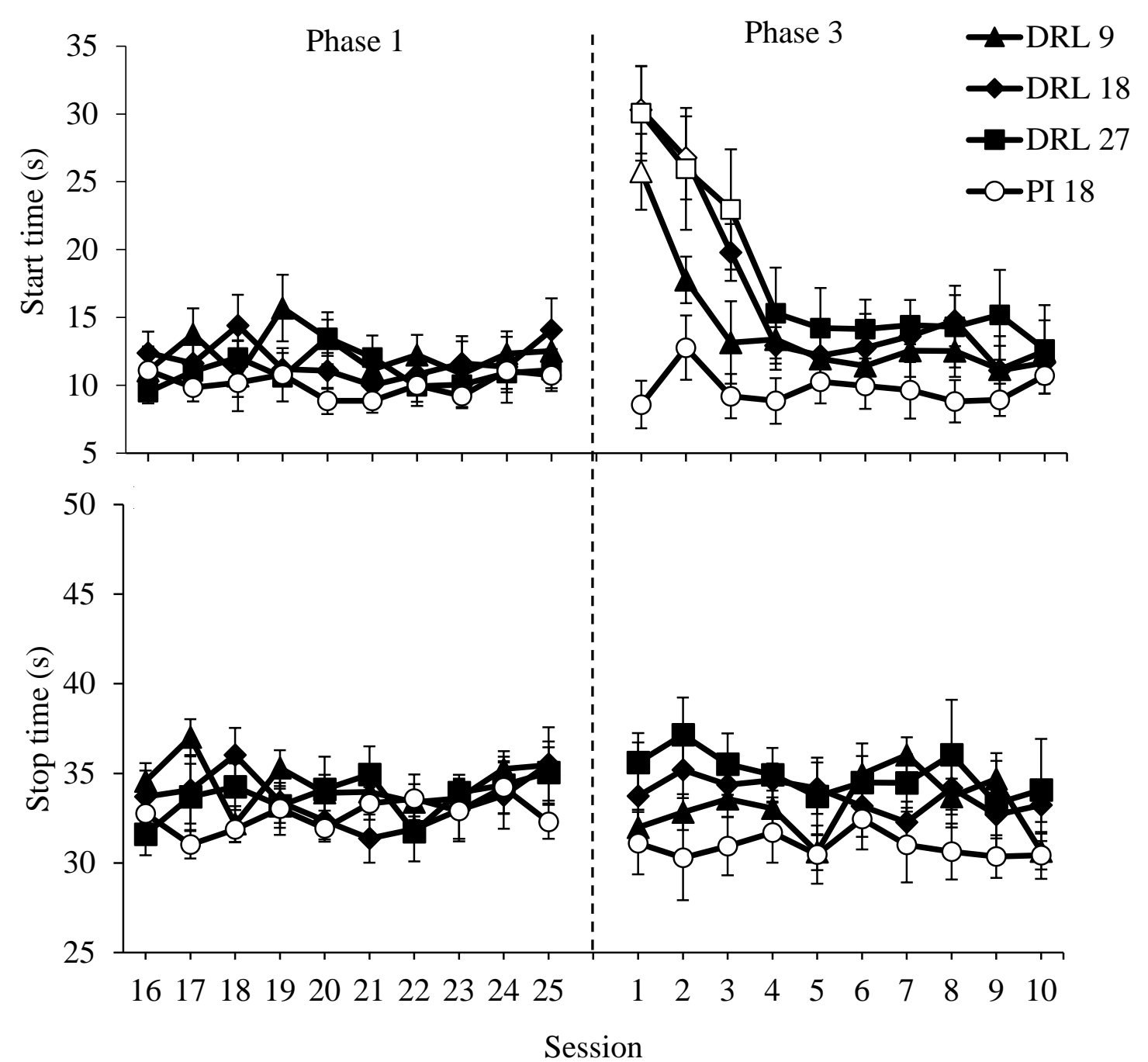

Figure 4. Top panel: Mean $( \pm S E M)$ start time for each group during the last 10 sessions of Phase 1 and the first 10 sessions of Phase 3. Bottom panel: Mean $( \pm S E M)$ stop time for the same sessions as the top panel. Unfilled data points (excluding PI 18) indicate a significant difference from the Phase 1 terminal average, $p<.05$. 

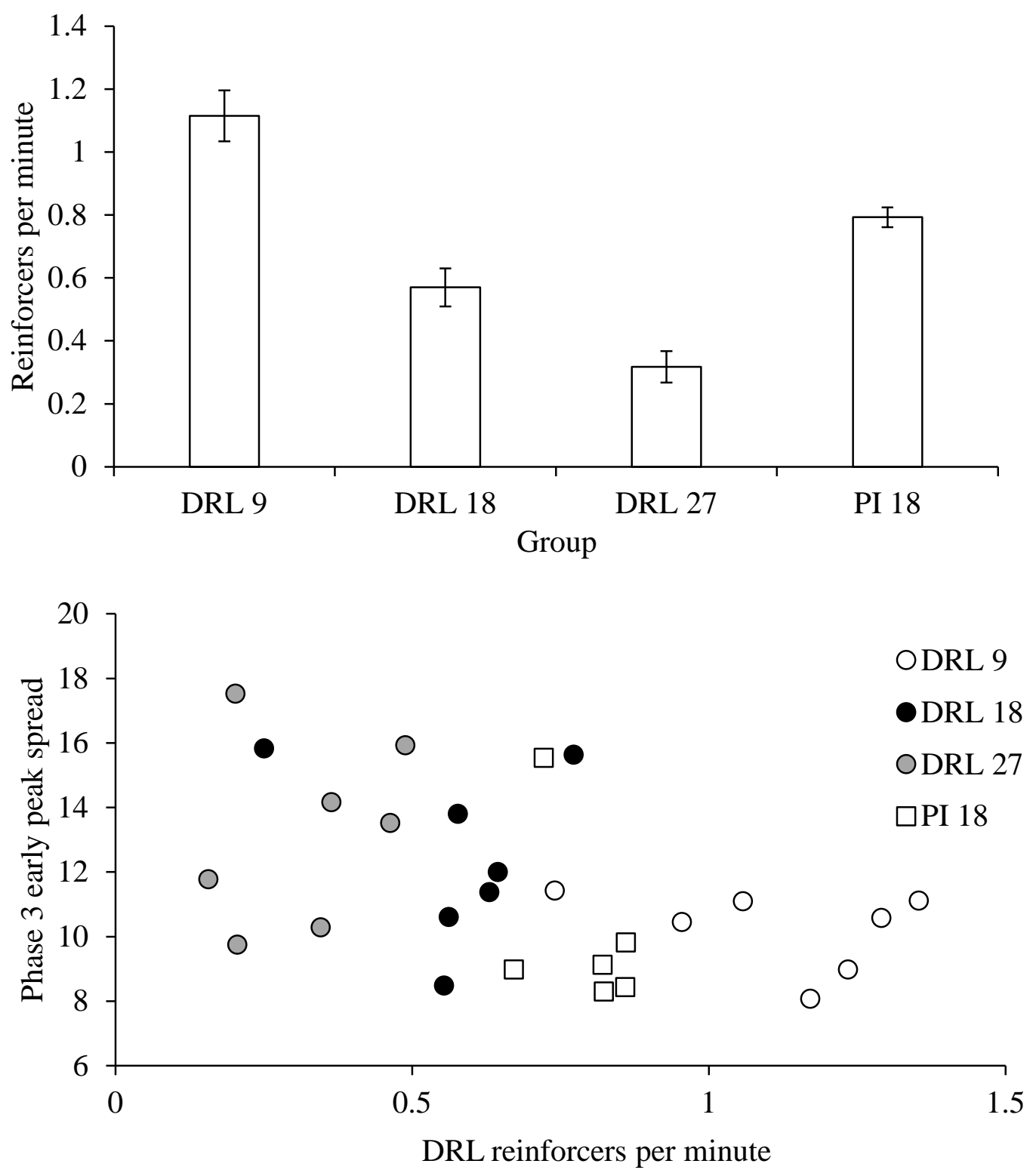

Figure 5. Top panel: Mean $( \pm S E M)$ reinforcement rate for each group during the last five DRL sessions. Bottom panel: Reinforcement rate during the last five DRL sessions plotted as a function of peak spread at the first post-DRL time point for each mouse. The PI-18, DRL-9, DRL-18, and DRL-27 groups are denoted by the white squares, white circles, black circles, and grey circles, respectively. 


\section{Appendix \\ Supplemental Tables \& Figures}

Table A1. ANOVA results of the Gaussian analysis.

\begin{tabular}{|c|c|c|c|}
\hline & & Peak spread & \\
\hline & $F$ & $p$ & $\eta^{2}$ \\
\hline Group & 2.30 & .11 & .27 \\
\hline Pre-Post & 9.06 & $<.001$ & .32 \\
\hline \multirow[t]{3}{*}{ Group $\times$ Pre-Post } & 2.99 & .02 & .32 \\
\hline & & Peak time & \\
\hline & $F$ & $p$ & $\eta^{2}$ \\
\hline Group & .88 & .47 & .12 \\
\hline Pre-Post & 4.50 & .01 & .19 \\
\hline \multirow[t]{3}{*}{ Group $\times$ Pre-Post } & 1.93 & .10 & .23 \\
\hline & & Response rate & \\
\hline & $F$ & $p$ & $\eta^{2}$ \\
\hline Group & .35 & .78 & .05 \\
\hline Pre-Post & 2.55 & .09 & .12 \\
\hline Group $\times$ Pre-Post & 1.08 & .39 & .15 \\
\hline
\end{tabular}


Table A2. ANOVA results of the low-high-low analysis.

\begin{tabular}{|c|c|c|c|}
\hline & & Start time & \\
\hline & $F$ & $p$ & $\eta^{2}$ \\
\hline Group & 1.97 & .15 & .24 \\
\hline Pre-Post & 12.58 & $<.001$ & .39 \\
\hline \multirow[t]{3}{*}{ Group $\times$ Pre-Post } & 4.59 & $<.01$ & .42 \\
\hline & & Stop time & \\
\hline & $F$ & $p$ & $\eta^{2}$ \\
\hline Group & 2.20 & .26 & .26 \\
\hline Pre-Post & 9.49 & $<.001$ & .33 \\
\hline \multirow[t]{3}{*}{ Group $\times$ Pre-Post } & 4.03 & $<.01$ & .39 \\
\hline & \multicolumn{3}{|c|}{ High-state duration } \\
\hline & $F$ & $p$ & $\eta^{2}$ \\
\hline Group & .142 & .93 & .02 \\
\hline Pre-Post & 1.16 & .32 & .05 \\
\hline \multirow[t]{3}{*}{ Group $\times$ Pre-Post } & 2.24 & .06 & .26 \\
\hline & & Midpoint & \\
\hline & $F$ & $p$ & $\eta^{2}$ \\
\hline Group & 2.61 & .08 & .29 \\
\hline Pre-Post & 13.46 & $<.001$ & .41 \\
\hline Group $\times$ Pre-Post & 4.81 & $<.001$ & .43 \\
\hline
\end{tabular}



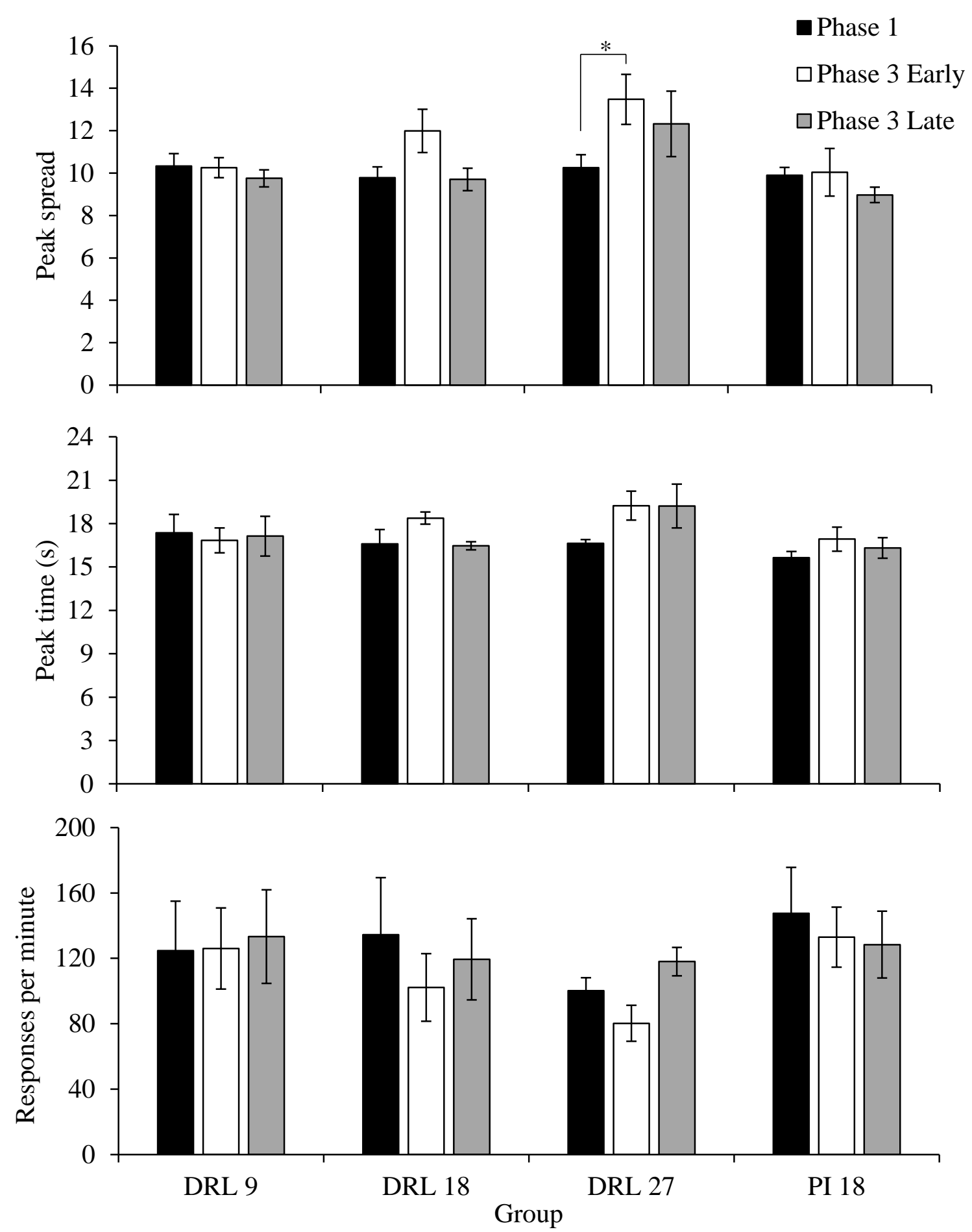

Figure A1. Results of the Gaussian analysis for each group at each time point. Top panel: Mean $( \pm S E M)$ peak spread. Middle panel: Mean $( \pm S E M)$ peak time. Bottom panel: Mean $( \pm S E M)$ response rate. Black bars show pre-DRL measures. White bars show measures during Phase 3 sessions $2-11$. Grey bars show measures of timing at the end of Phase 3 (sessions $16-25$ ). ${ }^{*} p<.05$ 

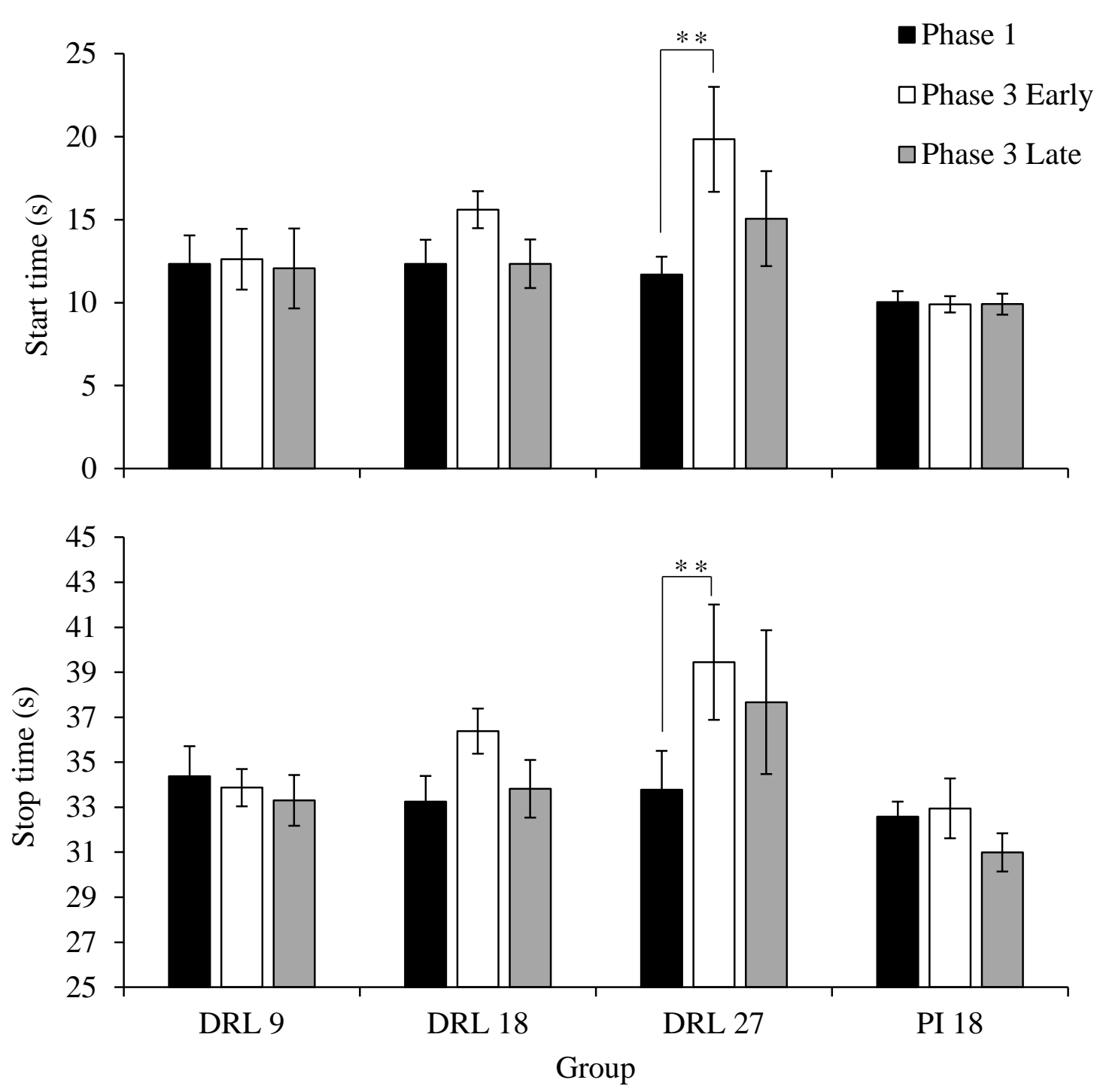

Figure A2. Results of the low-high-low analysis for each group at each time point. The top panel shows mean $( \pm S E M)$ start time. The middle panel shows mean $( \pm S E M)$ stop time. The bottom panel shows mean $( \pm S E M)$ high-state duration. The legend is identical to Figure 1. ${ }^{* *} p<.01$ 

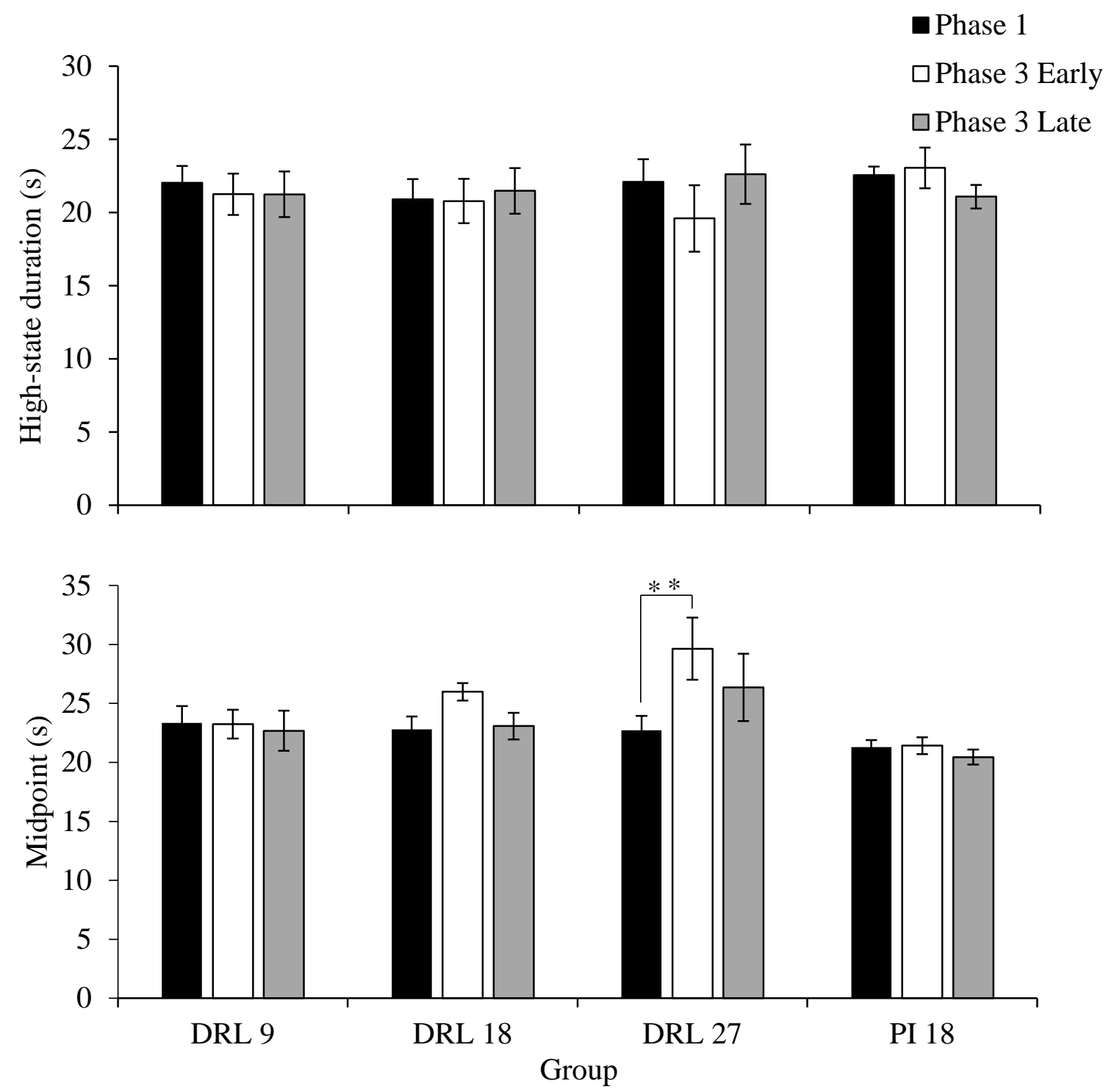

Figure A3. Top panel: Mean $( \pm S E M)$ high-state duration is plotted for each group at each time point. Bottom panel: Mean $( \pm S E M)$ midpoint is plotted for each group at each time point. The legend is similar to previous figures. ${ }^{* *} p<.01$ 


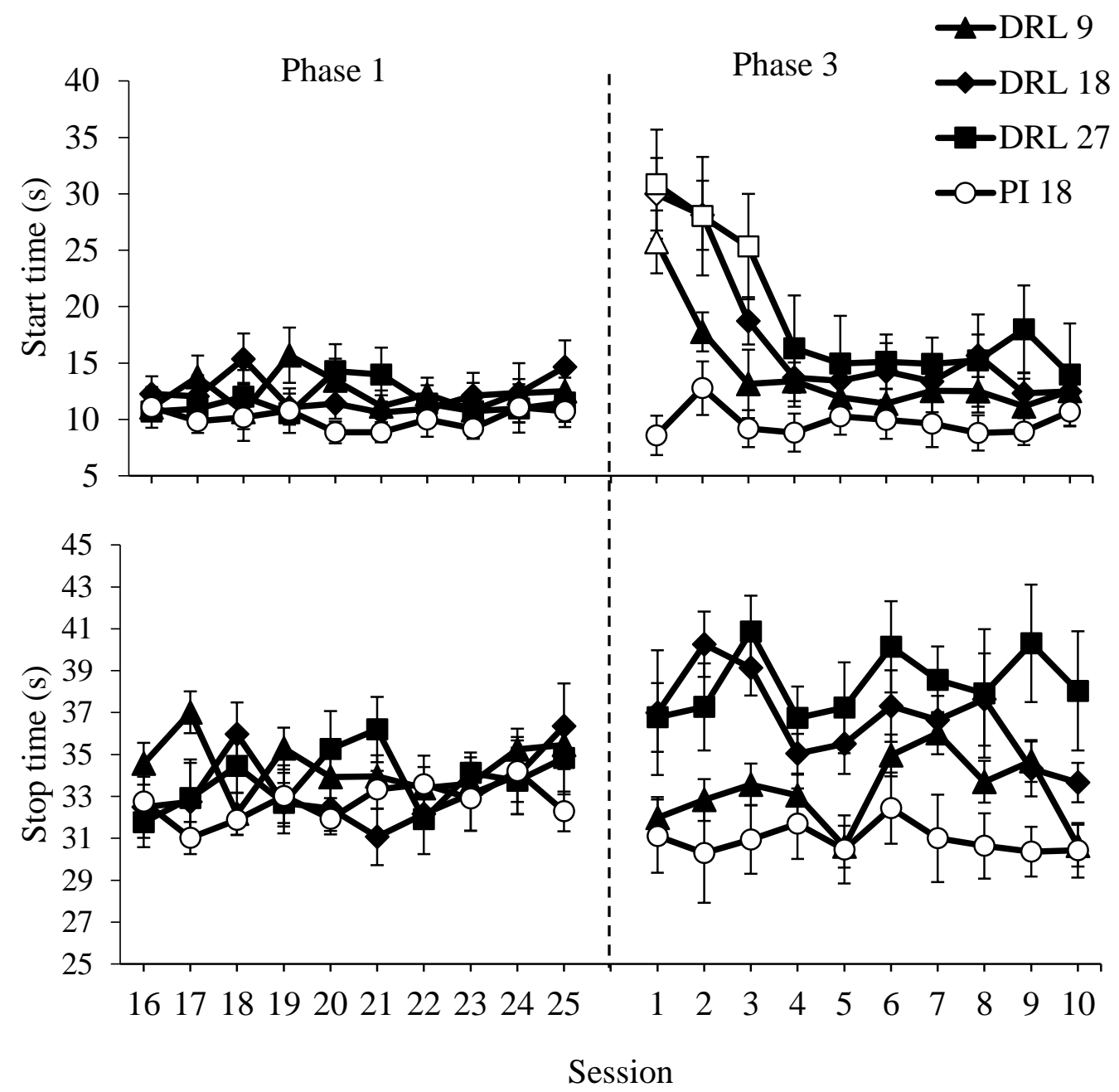

Figure A4. Top panel: Mean $( \pm S E M)$ start time for each group during the last 10 sessions of Phase 1 and the first 10 sessions of Phase 3. Bottom panel: Mean $( \pm S E M)$ stop time for the same sessions as the top panel. Unfilled data points (excluding PI 18) indicate a significant difference from the Phase 1 terminal average, $p<.05$. 

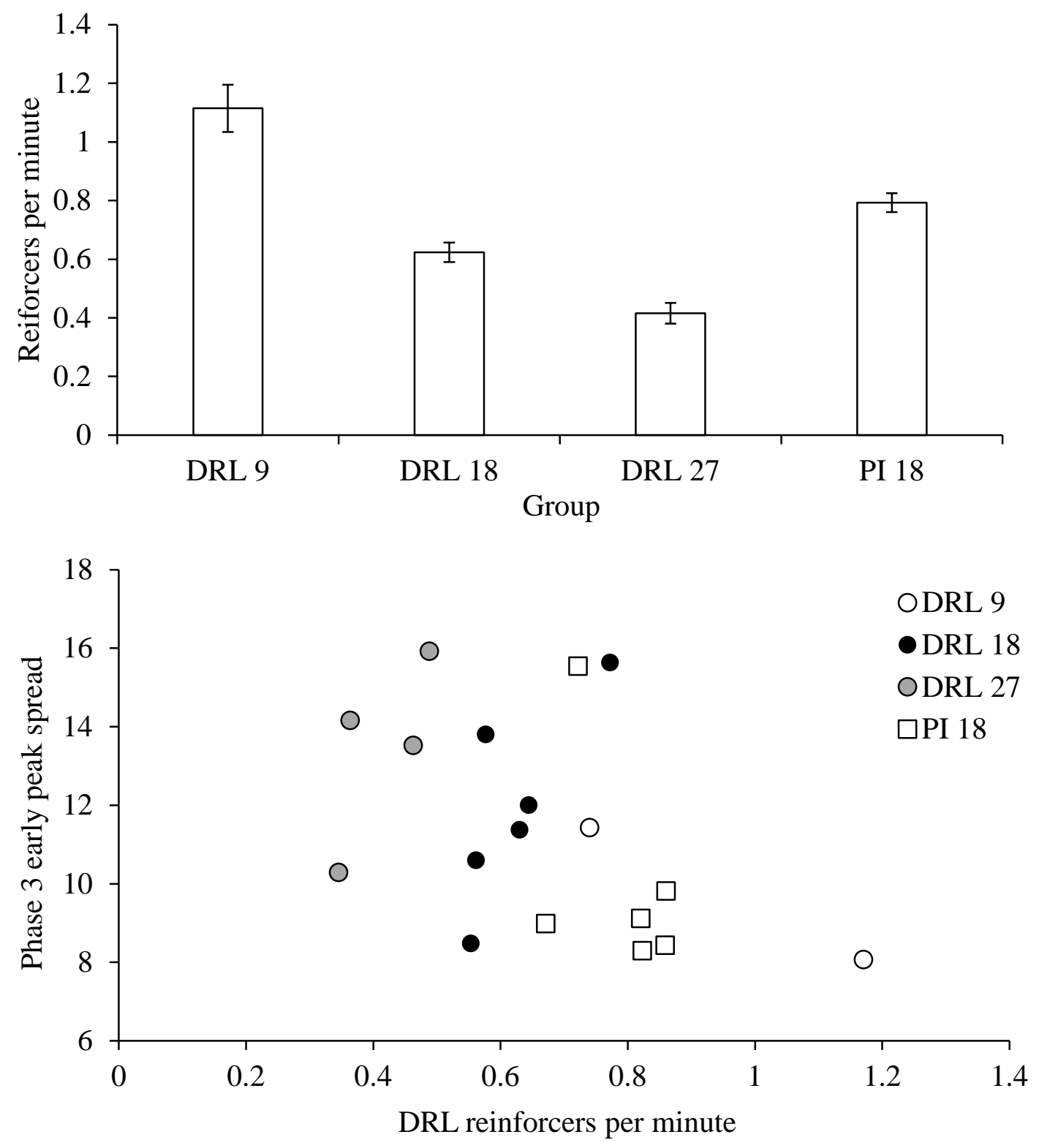

Figure A5. Top panel: Mean $( \pm S E M)$ reinforcement rate for each group during the last five DRL sessions. Bottom panel: Reinforcement rate during the last five DRL sessions plotted as a function of peak spread at the first post-DRL time point for each mouse. The PI-18, DRL-9, DRL-18, and DRL-27 groups are denoted by the white squares, white circles, black circles, and grey circles, respectively. 